PCIT engagement and persistence among child welfare-involved families: Associations with harsh parenting, physiological reactivity, and social cognitive processes at intake

\author{
Amanda Skoranski, Ph.D. ${ }^{1}$ \\ Elizabeth A. Skowron, Ph.D. ${ }^{1}$ \\ Akhila K. Nekkanti, M.S. ${ }^{2}$ \\ Carolyn M. Scholtes, M.Ed. ${ }^{2}$ \\ Emma R. Lyons, M.S. ${ }^{2}$ \\ Dave S. DeGarmo, Ph.D. ${ }^{3}$ \\ ${ }^{1}$ Department of Psychology \\ ${ }^{2}$ Department of Counseling Psychology \& Human Services \\ ${ }^{3}$ Department of Educational Methodology, Policy, \& Leadership \\ University of Oregon
}

Correspondence concerning this article should be addressed to Elizabeth Skowron, University of Oregon, 437 Straub Hall, Eugene, OR 97401. Telephone number: 541-346-9329. Email: eskowron@uoregon.edu

Acknowledgements: Financial Support. This research was funded by the National Institutes of Health through National Institute on Drug Abuse Grant R01-DA036533 (E.A.S.) and National Center for Advancing Translational Sciences Grant TL1TR002371 (A.K.N. Pre-Doctoral Fellow).

Conflicts of Interest: None. 


\begin{abstract}
Parent-Child Interaction Therapy (PCIT) has been shown to improve positive, responsive parenting and lower risk for child maltreatment (CM), including among families who are already involved in the child welfare system. However, higher-risk families show higher rates of treatment attrition, limiting effectiveness. In $N=120$ child welfare families randomized to PCIT, we tested behavioral and physiological markers of parent self-regulation and socio-cognitive processes assessed at pre-intervention as predictors of retention in PCIT. Results of multinomial logistic regressions indicate that parents who declined treatment displayed more negative parenting, greater perceptions of child responsibility and control in adult-child transactions, respiratory sinus arrhythmia (RSA) increases to a positive dyadic interaction task, and RSA withdrawal to a challenging, dyadic toy clean-up task. Increased odds of dropout during PCIT's Child-Directed Interaction phase were associated with greater parent attentional bias to angry facial cues on an Emotional Go/No-Go task. Hostile attributions about one's child predicted risk for dropout during the Parent-Directed Interaction phase, and readiness for change scores predicted higher odds of treatment completion. Implications for intervening with child welfareinvolved families are discussed along with study limitations.
\end{abstract}

Keywords: Parent-Child Interaction Therapy; Emotion Regulation; Respiratory Sinus Arrhythmia; Parent Attributions; Child Welfare 


\section{PCIT engagement and persistence among child welfare-involved families: Associations with harsh parenting, physiological reactivity, and social cognitive processes at intake}

Child maltreatment $(\mathrm{CM})$ remains a problem of high importance in the U.S., with dire consequences for children's developmental competencies, particularly socioemotional and relational outcomes (Lupien, McEwen, Gunnar, \& Heim, 2009; Toth, Gravener-Davis, Guild, \& Cicchetti, 2013). Parenting interventions such as Parent-Child Interaction Therapy (PCIT) have been shown to improve positive, responsive parenting and lower risk for $\mathrm{CM}$, including among families for whom CM has already been documented (Chaffin et al., 2004; Lieneman, Brabson, Highlander, Wallace, \& McNeil, 2017). Though PCIT is particularly effective among child welfare-involved families who engage in treatment, many such families are reluctant to engage in child and family interventions, and thus decline to enter treatment or drop out early (Burns et al., 2004). As such, understanding the potentially modifiable risk factors for child welfareinvolved families' treatment engagement and attrition is crucial for addressing CM as a public health concern. Modifiable risk factors for the perpetration of CM include deficits in self-control and emotion regulation, greater attunement to threat-related cues, and holding negative, threatsensitive attributions of children (Bugental, 1987; 2009; Skowron \& Woehrle, 2012). These characteristics in turn have been associated with deficits in sensitive, effective parenting strategies (e.g., Sturge-Apple, Davies, Cicchetti, \& Fittoria, 2014). In this study, we sought to examine whether these modifiable parental risk factors (e.g., self-regulation, social cognitions) also predicted persistence and dropout in PCIT among child welfare-involved families, and further examined whether there are distinct predictors of engagement in and persistence through key stages of PCIT. 


\section{Parent-Child Interaction Therapy (PCIT)}

Parent-Child Interaction Therapy (PCIT) is an active, directive behavioral parenting intervention wherein parents practice the behaviors taught in the intervention with their child during sessions. PCIT uses a unique "bug-in-the-ear" method where parents receive live coaching from a trained therapist to improve their parenting in real time. PCIT is divided into two phases - Child-Directed Interaction (CDI) and Parent-Directed Interaction (PDI). Phases are delivered sequentially, and each phase begins with a teaching session where parents learn and practice new parenting techniques, followed by several coaching sessions during which the parent receives live therapist support while practicing new skills with their child (Eyberg, 1988; Eyberg \& Funderburk, 2011; Funderburk \& Eyberg, 2010; Herschell \& McNeil, 2005). Further, coaching focus in PCIT is guided by observation of parents' developing skills, informed by brief coding at the outset of each weekly session.

The CDI phase of treatment focuses on strengthening warm, positive relationships between parents and children. Parents are taught to: 1) use positive parenting (i.e., PRIDE) skills consisting of specific labeled praises for positive child behavior (e.g., "Great job picking up the toys!"), reflection of the child's speech and behavior, imitation, behavioral descriptions (e.g., "You're stacking the blocks on top of each other"), and demonstrating enjoyment of time spent together; 2) follow their child's lead in the play; and 3) avoid use of "Don't Skills" that include negative talk/criticism and parent directives during the play. In the PDI phase of treatment, parents learn safe, effective child behavior management strategies that center around giving simple, developmentally-appropriate, direct commands (e.g., "Please sit down on your chair") instead of commands that focus on what not to do (e.g., "Cut it out!") or that take the form of indirect suggestions for how to behave (e.g., "Do you want to sit down now?"). Parents are then 
coached to follow through with either praise for child compliance (e.g., "Great job listening!") or a safe and consistent time-out procedure for noncompliance. These child behavior management skills are designed to replace harsh or inconsistent forms of discipline often observed among families with histories of child maltreatment.

PCIT is particularly well-suited for families with a history of CM (Chaffin et al., 2004; see meta-analyses by Euser et al., 2015; Kennedy et al., 2016). Maltreating parents may resort to physical punishment during episodes of discipline as a consequence of escalating coercive behavior between parent and child (Hershell \& McNeil, 2005; Patterson, 2002). Implementing the skills taught in PCIT helps to disrupt coercive cycles and reduce harsh, aversive parenting by providing caregivers with alternative, non-violent discipline strategies (e.g., Hakman, Chaffin, Funderbunk, \& Silovsky, 2009). PCIT enables caregivers to effectively discipline their child while avoiding use of harsh punishment. However, development of positive parenting skills and safe, effective child behavior management skills is likely aided by certain competencies, such as regulating negative arousal in stressful disciplinary contexts and inhibiting the tendency to "give in" to child aversive behavior (Skowron \& Funderburk, in preparation).

\section{Predictors of Attrition in Family-Based Interventions}

PCIT is effective when families engage, but as is the case for family-based interventions in general and with high-risk families in particular, attrition rates are high (Danko, Garbacz, \& Budd, 2016). On average, studies of family-based interventions report estimates of $40-60 \%$ attrition (Prinz \& Miller, 1994; Reyno \& McGrath, 2006; Wierzbicki \& Pekarik, 1993). Comparatively, reports of attrition rates in PCIT range from $18 \%$ to $74.5 \%$ (Eyberg, Boggs, \& Algina, 1995; Eyberg et al., 2001; Fernandez \& Eyberg, 2009; Lieneman, Quetsch, Theodorou, Newton, \& McNeil, 2019; Nixon, Sweeney, Erickson, \& Touyz, 2003; 2004; Schuhmann, Foote, 
Eyberg, Boggs, \& Algina, 1998). Sociodemographic factors are among the most common barriers to treatment retention in family-focused interventions (Kazdin, 1996; Kazdin, Mazurick, \& Bass, 1993), including educational attainment, single parenthood, and income (Danko et al., 2016; Fernandez \& Eyberg, 2009; Gross, Belcher, Budhathoki, Ofonedu, \& Uveges, 2018). Family-centered therapies also must contend with accessibility issues (Comer et al., 2017), and parent factors such as parenting stress (Kazdin \& Mazurick, 1994) and history of psychopathology (Gross et al., 2018; Kazdin et al., 1993; Werba, Eyberg, Boggs, \& Algina, 2006).

As is the case with other evidence-based family interventions, patterns of engagement and attrition in PCIT may depend on the family's presenting concerns and the manner in which PCIT is delivered. For example, lower attrition rates are generally reported among lower-risk families with children presenting with disruptive behavior concerns (Nixon et al., 2003, 2004). Perhaps not surprisingly, higher-risk families, such as those referred for treatment by child welfare services, show higher rates of treatment attrition (e.g., Lanier et al., 2011). Studies of treatment persistence and dropout in PCIT also vary considerably in how attrition is defined, further complicating matters. For example, in studies of attrition in mastery-based PCIT (i.e., in which sessions continue until parents meet criteria for skills mastery), treatment dropout is defined as leaving treatment prior to reaching skills mastery. Thus, families may be considered “dropouts" even after attending more than 25 sessions. By contrast, studies of time-limited PCIT employed in randomized clinical trials define attrition as dropping out before the total number of sessions available to a family, which may be far fewer in some cases. These differences in conceptualizing the timing of attrition deserve careful attention in studies of PCIT dropout and treatment effectiveness, given that PCIT is effective in modifying children's behavioral problems 
even among families who fail to meet PCIT mastery (e.g., Chaffin et al., 2004; Lieneman et al., 2019).

Some studies of attrition from PCIT document a host of sociodemographic predictors, including single parent status, employment, and lower parent educational levels and income (e.g., Bagner \& Graziano, 2013; Fernandez \& Eyberg, 2009; Gross et al., 2018). However, other studies found that SES factors were not significant when factors such as parenting stress were also considered (Capage, Bennett, \& McNeil, 2001; Werba et al., 2006). In addition, some evidence suggests that greater levels of observed negative parenting at treatment-entry may increase odds of dropout from time-unlimited, mastery-based PCIT (Fernandez \& Eyberg, 2009; Lieneman et al., 2017).

\section{Identifying Predictors of PCIT Attrition in Child Welfare-Involved Families}

Few studies have examined predictors of attrition from PCIT in child welfare populations. Many sociodemographic risk factors for dropout from various family-based interventions are shown to be more prevalent in child welfare-involved families (e.g., single parent status, lower income levels; Gopalan et al., 2011), though notably such sociodemographic factors are not easily intervened upon. Randomized clinical trials of PCIT for child maltreating families generally employ shorter, standard-length protocols for treatment averaging 16-20 sessions (Chaffin et al., 2004; Nekkanti et al., 2020; Thomas \& Zimmer-Gembeck, 2012), however few of these studies have examined predictors of attrition. Among these, Thomas and Zimmer-Gembeck (2012) found retention was unrelated to sociodemographic factors. Discovery of new, potentially modifiable predictors of dropout and retention is critically important to inform efforts to support persistence in PCIT treatment among child welfare-involved families and improve outcomes for children and families who may need it the most. 
In the current study, we focused our attention on individual difference factors known to heighten risk for child maltreatment (CM) perpetration, namely, behavioral and physiological markers of parent dysregulation and maladaptive socio-cognitive processes (described below). We reasoned that these difficulties also may leave families more vulnerable to non-engagement or at increased risk for dropping out of PCIT, and thus, sought to test these as predictors of dropout and persistence in child welfare-involved families. Furthermore, because few studies of treatment retention in family-based interventions have considered timing of dropout (cf. Gross et al., 2018), another aim of this study was to examine the timing of dropout in PCIT to better understand differential predictors of treatment engagement and retention in PCIT for child welfare-involved families. At the time of this study, we were aware of no published studies examining this collection of individual difference predictors of PCIT engagement nor of efforts to differentiate predictors of non-engagement, early- and late-stage dropout, and treatment completion, among child welfare-involved families.

\section{Parent Self-Regulation}

Inhibitory Control. Self-regulation skills facilitate flexible and intentional behavior that is essential for warm, responsive parenting, whereas parent dysregulation highlights risk for perpetrating child maltreatment and other forms of harsh parenting (Fontaine \& Nolin, 2012; Skowron, 2015). One aspect of self-regulation, inhibitory control, enables parents to flexibly respond to their children by switching or alternating their attention as needed, and inhibiting automatic behavioral responses in favor of alternatives that better suit the child's needs and situational demands. For example, a tired and stressed parent with good inhibitory control skills might consciously refrain from yelling "stop it!" at their child when they find her jumping on the couch in muddy shoes, and instead, calmly instruct their child "please sit down on your bottom 
and take off your shoes." Prior studies have found clear links between inhibitory control in parents and sensitive, involved parenting (e.g., Crandall, Deater-Deckard, \& Riley, 2015), use of effective discipline strategies (Chen \& Johnston, 2007), and responding positively to children's negative emotion (Valiente, Lemery-Chalfant, \& Reiser, 2007). Conversely, poor inhibitory control is associated with the use of harsh, aversive parenting (Deater-Deckard, Wang, Chen, \& Bell, 2012) and increased CM risk (Crandall et al., 2015; Fontaine \& Nolin, 2012).

Parent coaching in early PCIT sessions (i.e., CDI phase) often involves searching for positive child behaviors to praise while purposefully ignoring children's negative, attentionseeking behaviors (e.g., grabbing, yelling) and other minor misbehavior. In later PCIT sessions (i.e., PDI phase), parents must inhibit harsh, reactive responses to disobedient child behavior in order to follow a sensitive discipline protocol, making inhibitory control particularly important for treatment success. Given the natural demands of parenting on parents' self-regulation skills together with documented deficits in self-control among CM parents, we sought to test whether parents' pretreatment self-regulation skills and social cognitions would predict PCIT engagement and persistence in the current study.

Respiratory Sinus Arrhythmia. In addition to behavioral measures of parent selfregulation (e.g., inhibitory control), respiratory sinus arrhythmia (RSA) represents a peripheral physiological marker of regulation. Bagner and colleagues have investigated RSA responding in PCIT with premature infants (e.g., Bagner et al., 2009; Graziano, Bagner, Sheinkopf, Vohr, \& Lester, 2012), however to our knowledge, no studies to date have investigated parent RSA as an predictor of engagement and persistence in PCIT. RSA is a measure of the cyclical oscillations in heart rate (HR) across successive respiratory cycles (i.e., HR acceleration during inhalation and HR deceleration during exhalation), and indexes parasympathetic nervous system (PNS)-linked 
cardiac activity (Task Force of the European Society of Cardiology, 1996). RSA values are used frequently to assess physiological activity at rest and change in RSA from resting conditions to emotionally evocative contexts, such as in parent-child interactions.

Lower resting RSA is thought to reflect deficits in top-down control of self- and emotionregulation and has been observed in both child welfare-involved parents (Creaven, Skowron, Hughes, Howard, \& Loken, 2014; Skowron et al., 2011), parents at risk for perpetrating child physical abuse (Crouch et al., 2015), and a wide range of psychopathology (Beauchaine, 2015). In terms of RSA reactivity to emotionally evocative events, excessive RSA withdrawal (i.e., decreases in RSA from baseline levels) in stressful contexts is linked to range of psychopathology (Beauchaine, Bell, Knapton, McDonough-Caplan, Shader, \& Zisner, 2019). Previous research has shown that parents who display more negative, aversive parenting behaviors evidence lower RSA scores (i.e., greater RSA withdrawal) during interactions with their children (Lorber \& O’Leary, 2005; Smith, Woodhouse, Clark, \& Skowron, 2016). In contrast, parents who display warm, responsive parenting show higher RSA during mutually positive interactions with their children (Augustine \& Leerkes, 2019; Smith et al., 2016), and greater RSA withdrawal while interacting with their distressed children (i.e., following the stillface paradigm; Ablow, Marks, Shirley Feldman, \& Huffman, 2013; Joosen, Mesman, Bakermans-Kranenburg, \& van Ijzendoorn et al., 2013; Leerkes, Su, Calkins, Supple, \& O'Brien, 2016).

Numerous studies indicate that child welfare-involved parents show heightened physiological reactivity to their children (McCanne \& Hagstrom, 1996), with some recent work suggesting these parents may experience positive parent-child interactions as physiologically taxing. For example in a study of CM families, Skowron and colleagues (2013) documented a 
pattern of decreasing RSA scores in physically abusive mothers while they engaged in positive play with their child, and links between RSA withdrawal and subsequent increases in harsh, aversive parenting moments later in the interaction (Skowron, Cipriano-Essel, Benjamin, Pincus, \& Van Ryzin, 2013). In another study with the same CM families, Norman Wells et al. (2020) found that physically abusive mothers responded to their children's prosocial bids for guidance with subsequent RSA withdrawal, whereas non-maltreating mothers responded to their child bids for guidance with increasing RSA (i.e., greater physiological calm; Norman Wells, Skowron, Scholtes, \& DeGarmo, 2020). Together these findings suggest that one reason CM parenting is so difficult to modify may be because physiological reactivity appears to fuel aversive parenting. We reasoned that parents' RSA responding during emotionally evocative interactions with their children, namely less RSA activation during a positive social engagement task and less RSA withdrawal during a more challenging toy clean-up task may predict risk for dropout.

\section{Parent Social Cognitive Processes}

Attributions about Child. Parental attributions or the ways parents interpret and evaluate their child and their child's behavior (Beckerman, van Berkel, Mesman, \& Alink, 2017), may influence parents' willingness to engage and persist in PCIT. Studies show that parents who think of their children in positive, developmentally-sensitive ways tend to engage in warm, responsive parenting and enjoy parenting more (Beckerman, van Berkel, Mesman, Huffmeijer, \& Alink, 2019; Hastings \& Rubin, 1999). In contrast, parents who hold negative attributions of their children, and consequently view their children as intentionally misbehaving, deliberately hostile, controlling, and acting with malice, are more likely to engage in harsh parenting, acts of child physical abuse (Azar \& Twentyman, 1986; Bradley \& Peters, 1991; Bugental, 2009; Larrance \& Twentyman, 1983), and dropout from family-based interventions (Mattek, Harris, \& 
Fox, 2016). As such we hypothesized that negative parent attributions might also predict risk for family dropout from PCIT.

Threat-Related Attentional Bias. CM parents' show heightened vigilance to threat detection and tend to privilege attention to negative emotional cues during caregiving interactions. Meta-analysis has shown that anxious adults and children both display threat-related attentional bias, and overgeneralize anger to neutral stimuli (Bar-Haim, Lamy, Pergamin, Bakermans-Kranenburg, \& van Ijzendoorn, 2007), or in the case of CM-exposed children, recognize facial displays of anger more quickly than their non-maltreated peers (e.g., Pollak, Cicchetti, Hornung, \& Reed, 2000; Pollak, Klorman, Thatcher, \& Cicchetti, 2001). However, to our knowledge, no research to date has studied the effects of threat-related attentional biases on parent engagement or success in parenting interventions, and in particular among child welfare involved parents. We reasoned that parents who tend to overgeneralize perceptions of anger when exposed to neutral facial cues may find it more difficult to perceive positive changes in their child's behavior or recognize increasing warmth and positive connection in their relationship with their child. In this way, we predicted parents with greater threat-related attentional bias would be at greater risk for dropout from PCIT.

Readiness for Change. Parents' readiness or motivation for change has been examined as a predictor of PCIT treatment engagement in child welfare-involved families (e.g., Chaffin et al., 2009). Readiness for change may be linked with parental attributions; if parents believe that their behavior has an impact on children's challenging behaviors, they may be more willing to engage in parenting treatment. One study found that for parents who expressed lower readiness to change, engagement in a "motivational enhancement" session prior to the start of PCIT increased treatment retention (Chaffin et al., 2009). However, enhancing motivation does not always 
promote treatment engagement among child welfare-involved families, which may suggest that other factors are at play in determining treatment engagement (Webb, Thomas, McGregor, Avdagic, \& Zimmer-Gembeck, 2017). One explanation for diverging findings is that motivation is an important factor for choosing to enter treatment rather than sticking with treatment (or vice versa). More research is necessary to test whether parents' readiness to change impacts attrition to a different extent depending on the stage of treatment.

\section{Current Study}

There is a paucity of research on predictors of engagement and persistence in PCIT among child welfare-involved families. Given that PCIT is effective as well as cost-effective (Aos, Lieb, Mayfield, \& Miller, 2004), better identification of predictors of treatment persistence could inform strategies to extend the reach of this program which has significant implications for public health and safety for children. In the current study, we tested whether parents' selfregulation skills and social-cognitive processes at pre-treatment play an important role in whether child welfare-involved families persist in PCIT or are at risk for dropping out. We theorized that these factors which confer risk for $\mathrm{CM}$ also pose challenges for family engagement in PCIT. Thus, we tested whether markers of parent self-regulation (i.e., inhibitory control, RSA responses during mutually positive and challenging dyadic interaction task, and self-reported executive functions), and social-cognitive processes (i.e., quality of parent attributions, threat sensitivity, and readiness for change) would predict engagement and attrition in PCIT for a sample of child welfare-involved families. We hypothesized that greater parent self-regulatory skills and more adaptive social cognitions would predict persistence in PCIT.

Next, we operationalized treatment persistence using four ordinal categories to distinguish families who (1) declined to engage in PCIT, (2) dropped out during the CDI phase, 
(3) dropped out during the PDI phase, and (4) completed treatment, and treated these analyses to be exploratory in nature. To our knowledge, this is the first study of PCIT in child welfare families to consider parent self-regulatory and socio-cognitive processes as predictors of PCIT attrition across four different stages of treatment.

\section{Method}

\section{Participants}

The present study is an NIH-funded randomized clinical trial investigating the biological and behavioral mechanisms of change in Parent-Child Interaction Therapy among a sample of child welfare-involved families. Participants were recruited directly through the Department of Human Services (DHS) by their child welfare or self-sufficiency caseworkers. Eligible families met the following criteria at study enrollment: 1) the parent was $18+$ years old, 2) the parent was the participating child's biological parent or custodial caregiver, 3) the child was 3-7 years old, 4) the participating parent and all caregivers in the home had no prior documented history of perpetrating child sexual abuse, and 5) the parent provided written informed consent for both themselves and their child to participate. Participants included 204 child welfare-involved parents and their 3-7-year-old children. Of these families, 120 were randomly selected to receive PCIT and were included in the analyses in the present study. (For more information on the larger clinical trial, including recruitment information, the services-as-usual control group, and further study protocol, please see the study protocol in Nekkanti et al., 2020.)

Of this intervention subsample of 120 participants, $89 \%$ of parents were mothers $(11 \%$ fathers), and 67.5\% were White/European American, 22.5\% were Multi-Ethnic, 2.5\% were Latinx/Hispanic American, 2.5\% were Pacific Islanders, 1.7\% were Black/African American, $0.8 \%$ were Native American/Alaskan Native, and 2.5\% were of unknown race/ethnicity or did 
not report. Average parent age was 32.4 years, with a range of 18-64 years, and average child age was 4.7 years, with a range of 3-8 years. The mean household income for families was $\$ 19,046$ per year and ranged from $\$ 0$ to $\$ 66,000$ annually. With regard to educational attainment, $0.8 \%$ of parents had less than an $7^{\text {th }}$ grade education, $2.5 \%$ completed junior high school, $13.3 \%$ completed partial high school, 48.4\% completed high school or GED, 13.3\% completed technical or vocational training, $15 \%$ completed an associate's or junior college degree, $5 \%$ completed a bachelor's degree, and $1.7 \%$ completed a graduate degree. The large majority of participating caregivers $(\mathrm{N}=117,97.5 \%)$ were biological parents of the child, one was an adoptive parent, and two were grandparents.

\section{Procedure}

Dyads randomized to receive PCIT participated in assessments conducted at 3 timepoints: Time 1 (pre-treatment), Time 2 (mid-treatment), and Time 3 (post-treatment). All assessment visits included parent-child dyadic interaction tasks, individual child tasks, individual parent tasks, and parent reports of their own functioning, their child's functioning, sociodemographic characteristics, and the parent-child relationship. Cardiac physiology was monitored for both parents and children at resting baseline, during solo tasks, during parent-child interaction tasks, and during recovery periods following all tasks. For all assessments, tasks were split across two visits to the lab scheduled approximately one week apart. The present study utilizes data collected at Time 1 (pre-treatment) to predict persistence and dropout in the PCIT intervention. Families were randomized to the PCIT treatment group or a Family Services as Usual (SAU) control condition upon completion of their Time 1 assessment via a double-blind, sealed letter. Overallocation to the PCIT condition occurred at a rate of approximately 1.5:1. Families in the SAU condition received only the services typically provided by child welfare 
agencies, including in-home family visitation, respite childcare, individual child counseling, and/or parent training. Families were compensated $\$ 90$ for completing the first visit and $\$ 65$ for completing the second visit, and received childcare, snacks, a gift for the participating child and $\$ 10$ for transportation costs at each visit.

\section{Pretreatment, Visit 1}

At the initial 2.5-hour visit, parents completed the informed consent procedures and then parent and child were fitted with seven disposable pre-gelled electrodes to record electrocardiogram (ECG). ECG electrodes were placed in a modified Lead II arrangement on the right clavicle, lower left rib, and lower right abdomen. The remaining four electrodes were used to collect impedance data. ECG data was wirelessly transmitted via an ambulatory impedance cardiograph (Mindware Technologies, Westerville, OH, USA) to a desktop computer. Parents and children each wore a vest containing their own Mindware mobile device throughout the entirety of the visit to allow for freedom of movement during the study tasks. All tasks were videotaped for offline behavioral coding.

Dyadic Interaction Tasks. Following electrode placement, a 3-minute resting baseline of parent and child cardiac physiology was collected while the dyad sat together quietly, without touching, and watched a neutral video.

Next, dyads participated in the standardized PCIT Dyadic Assessment Protocol (Eyberg \& Funderburk, 2011), using a standard set of toys in the lab's playroom. Parents received task instructions via a microphone earpiece while they were alone in the room with their child. The PCIT Dyadic Assessment Protocol consists of three standardized 5-minute tasks: child-led play, parent-led play, and clean-up. Parents were instructed to follow their child's lead during the first portion, then were told to lead the play and attempt to gain their child's compliance during the 
second portion. During clean-up, parents were instructed to have their child clean up all the toys in the playroom without physically helping their child put the toys away. Of these three phases of PCIT, respiratory sinus arrhythmia (RSA) was examined only during the clean-up task for the current study (i.e., referred to below as the 'challenge task'), as it was believed to be the most challenging task and prior work has shown that similar tasks produce the greatest parasympathetic withdrawal responses in parents and children (Lunkenheimer, Tiberio, Skoranski, Buss, \& Cole, 2018). Following this interaction, dyads participated in a 2-minute joint recovery while watching the same neutral video as was shown during the resting period.

Next, dyads participated in the Social Engagement Task (SET; adapted from Weismer Fries, Ziegler, Kurian, Jacoris, \& Pollak, 2005). This task was designed to assess attachmentrelated neurophysiology from institutionalized children who experienced early neglect when paired with their adoptive caregivers. Parents and children sat in close physical proximity and completed three interactive tasks: 1) gently pointing to features of one another's face (e.g., nose, ears, hair, etc.), 2) touching and counting one another's fingers, and 3) taking turns softly whispering a story in each other's ears. Each task was presented for a fixed time interval and the activity order remained consistent across dyads. Parents' average RSA was assessed during the duration of the SET as a measure of parasympathetic physiology during a positive, prosocial activity with their child.

Finally, dyads received a brief break and were offered a snack prior to transitioning onto individual tasks. At that time, parents were taken to a separate assessment room in the lab and participated in two cognitive-behavioral tasks, described below.

\section{Pretreatment, Visit 2}


Families returned to the lab for a second 2-hour visit approximately one week following their initial appointment. During this visit, parents completed a variety of questionnaires while their child participated in individual tasks. Questionnaires administered assessed a variety of parent, child, and relational characteristics, including parent executive functioning (BRIEF-A), parent attributions of their child (PAT and SASB), and parents' readiness to change their parenting behavior (REDI; each described below). To account for variations in parent literacy, all questionnaires were read aloud to parents and their answers were entered into a laptop computer by a trained research assistant. Upon completion of this visit, families received a sealed letter randomizing them to either the PCIT treatment group or the SAU control condition. Families randomized to the PCIT treatment group received information on the basic structure and goals of PCIT as well as a brief tour of the PCIT clinical rooms.

\section{Intervention}

PCIT was delivered to families randomized to the intervention condition in three sequential modules: motivational enhancement (ME), Child-Directed Interaction (CDI), and Parent-Directed Interaction (PDI) in a 22-session standard length protocol consisting of $2 \mathrm{ME}$ sessions, and a maximum of 9 CDI sessions (1 teach, 8 coaching), and 11 total PDI sessions (1 teach, 10 coach). Four intervention families who enrolled early in the trial received greater than the 22 total sessions ( 23 to 30 sessions) due to extensions granted to help them try to achieve PCIT mastery. No family was denied fewer than 22 PCIT sessions. Families first received two individual ME sessions adapted from a six-week group-based model (Chaffin et al., 2004). Following ME, dyads participated in CDI, which promotes the development of positive parenting skills, then PDI, which promotes safe, effective child behavior management skills. During coaching sessions, parents wore a small earpiece and received live support, feedback, and 
guidance from the therapist, who watched the dyads' interaction from behind a one-way mirror. PCIT was delivered by 8 therapists, including 6 doctoral-level graduate students, a licensed social worker, and a licensed psychologist. Therapist training conformed to PCIT International standards for observed case practice and intervention fidelity criteria. All therapists received ongoing weekly remote consultation and live supervision of therapy sessions by master PCIT trainers at the University of Oklahoma. All sessions were videotaped, and therapists completed fidelity ratings at the end of each session. Independent raters blind to family outcomes also monitored ongoing fidelity to the treatment model by coding $15 \%$ of session videotapes.

\section{Measures}

\section{Executive Functioning}

Parents reported on their own executive functioning abilities on an abbreviated version of the Behavior Rating Inventory of Executive Function - Adult Version (BRIEF-A; Roth, Isquith, \& Gioia, 2005). The abbreviated BRIEF-A administered included 38 items and responses to each item were rated on a three-point frequency scale $(1=$ never, $2=$ sometimes, $3=$ often $)$. The Behavioral Regulation Index (BRI) was utilized in the current study and includes items from the Inhibit, Shift, Emotional Control, and Self-Monitor scales. Participants' self-ratings on these scales and indexes are characterized by T-scores $(M=50, S D=10)$, with higher scores indicating greater difficulty with behavioral regulation. Internal reliability for raw BRI ratings was strong among this sample (Cronbach's $\alpha=0.92)$.

\section{Inhibitory Control}

Parents completed two 6-minute blocks of the Stop Signal Task (Aron, Robbins, \& Poldrack, 2004) to assess response inhibition and impulse control. Each trial began with a cue indicating the start of a trial $(500 \mathrm{~ms})$, followed by an arrow pointing either left or right (at 1:1 
relative frequency) that served as the go signal $(1000 \mathrm{~ms})$, followed by an inter-trial interval of variable duration. Parents were instructed to press the left or right arrow indicated during each trial as quickly as possible in response to the go signal. On $25 \%$ of the trials, an auditory stop signal is played after the go signal at a variable latency known as the stop-signal delay (SSD). On trials where the stop signal was present, parents were instructed to withhold their button press. Each block of the task consisted of 128 trials, for a total testing time of approximately 12 minutes and 256 trials. A stop signal response time (SSRT) was calculated by first calculating the overall percent accuracy, and finding the SSD that corresponded to this percent accuracy, then taking the difference between the participant's reaction time on go trials at the percentile which corresponded with the participant's percent accuracy and this SSD, which reflects the efficiency of an individual's inhibitory control process (Aron et al., 2004). (For instance, if an individual achieved 52\% accuracy on the task, their SSRT would be calculated as the difference between their go reaction time at the $52^{\text {nd }}$ percentile and the SSD that corresponded with $52 \%$ accuracy.) Higher SSRT scores indicated slower reaction times (i.e., lower inhibitory control).

\section{Respiratory Sinus Arrhythmia}

ECG data were acquired using Mindware's Biolab (2.4) acquisition software, which integrates simultaneously recorded audio and video. Behavioral and procedural event markers were inserted into the physiological data stream during data collection to create time-locked behavioral and physiology data within tasks. Parent RSA was derived from high-frequency heart rate variability measured in the ECG $(0.12$ to $0.40 \mathrm{~Hz})$. RSA was measured in 30 -second epochs and averaged across tasks. Data were visually inspected and cleaned for movement artifacts and equipment errors offline using Mindware HRV Analysis software version 3.1.3. In the present study, parents' RSA was examined in three situations: the resting baseline, the dyadic toy clean- 
up (i.e., challenge) task, and the dyadic social engagement task (each described above). Baseline RSA was measured as the average parent RSA during the joint resting period. Two RSA reactivity scores were calculated: first, RSA reactivity for the challenge task was measured as the difference between parent RSA during the toy clean-up task and their baseline RSA. Parents' RSA reactivity for the social engagement task was similarly measured as the difference between parent RSA during the SET and their baseline RSA. In both cases, higher scores indicated RSA increases and lower scores indicated RSA withdrawal from baseline to task. We elected to use "raw" change scores rather than residualized change scores due to the fact that baseline RSA was also included as a predictor in our models, thus controlled for in the analysis of RSA change.

\section{Parental Attributions}

Structural Analysis of Social Behavior (SASB). The short form of the SASB Intrex questionnaires (Benjamin, Rothweiler, \& Critchfield, 2006) was used to assess parent perceptions of their child's harsh, controlling behavior toward them. Specifically, parents' responses on two items (Cluster 15 - "strict control” and Cluster 16 - "harsh, critical control”) from the Child with $\mathrm{Me}$ - Transitive scale were summed to create a total child harsh control toward parent score. Parents responded to each item with a score ranging from 0 (does not apply at all/never) to 100 (applies perfectly/all the time), thus, measures of harsh child control could range from 0 and 200.

Parent Attribution Test. The Parent Attribution Test (PAT; Bugental, Blue, \& Cruzcosa 1989) is a short questionnaire that utilizes vignettes to determine the amount of control an individual perceives themselves and a child as having during a hypothetical caregiving situation. Parents were asked about factors that may produce a successful vs. unsuccessful interaction with a hypothetical neighbor's child. Some factors place the locus of control with the parent (e.g., 
using the wrong approach for this child; being in a bad mood that day) while others place control with the child (e.g., the child was stubborn and resisted your efforts; the child made little effort to attend to what you said or did). Parents rated each factor on a 7-point Likert-type scale ranging from $1=$ Not at all Important to $7=$ Very Important. Average scores were then calculated for parents' perception of the parent being in control of disputes (referred to as 'parent control' in the current study) and parents' perception of the child being in control (referred to as 'child control'). Individual scores were used rather than a composite because the scores are not mutually exclusive, meaning that parents could rate both themselves and children as equally high or equally low on control.

\section{Threat-Related Attentional Bias}

The Emotional Go/No-Go task (Schulz et al., 2007; Schulz et al., 2009) was used to assess parents' attentional bias to angry facial cues. Parents were instructed to press a response key when a target emotion was presented and refrain from responding when a non-target emotion was presented. Stimuli included images of neutral, angry, happy, sad, and fearful facial expressions. Parents completed 8 blocks; during four blocks, neutral faces were the target expression, and during the four remaining blocks one of the four emotions (angry, happy, sad, or fearful) was the target expression. Each block consisted of 30 trials with 15 go trials and 15 nogo trials, making a total of 240 trials across all 8 blocks. The target designation was counterbalanced across each block of trials, such that target emotions were presented in a random order. Rates of correct responding (i.e., pressing the button when the target is presented, also referred to as "correct go's") and false alarms to distractors (i.e., pressing the button when the non-target stimulus is presented) were calculated. In the current study, the rate of false alarms 
to neutral facial displays during the angry target blocks was used to assess threat-related attentional bias, in which neutral expressions were misinterpreted as anger (Pollak et al., 2001).

\section{Readiness for Parenting Change}

The Readiness for Parenting Change (REDI; Mullins, Suarez, Ondersma, \& Page, 2004) was originally developed for substance-abusing parents involved in combined substance use and child welfare services and assesses motivation to change parenting. The REDI was adapted by Chaffin and colleagues (2009) by modifying items to reflect parent motivation for engaging in Parent-Child Interaction Therapy and adding items related to program content and goals of reducing harsh punishment, producing a 23 -item scale with an overall total score. Items on the adapted REDI measure parent readiness to change their parenting behavior, problem recognition, beliefs about harsh discipline, attitude towards participating in a parenting program, and selfefficacy. In the present study, total scores from the REDI were collected to assess parents' readiness to change across all assessed domains. The REDI scale has demonstrated high internal reliability in prior studies (e.g., Cronbach's $\alpha=0.84$; Chaffin et al., 2009). Reliability for the current sample of intervention participants was good, (Cronbach's $\alpha=0.81)$.

\section{Negative Parenting Behavior}

Video-recorded parenting behaviors were transcribed and observationally coded during the standard PCIT Dyadic Assessment Protocol (i.e., child-led play, parent-led play, and cleanup tasks) using the well-validated Dyadic Parent-Child Interaction Coding System, Fourth Edition (DPICS-IV; Eyberg, Nelson, Ginn, Bhuiyan, \& Boggs, 2013). In the present study, negative parenting behaviors were comprised of direct and indirect commands that took control during child-led play, and negative talk/criticisms coded during child-led play, parent-led play, and toy clean-up. Negative talk/criticism is defined by the DPICS-IV coding system as verbal 
expressions suggesting disapproval of a child's attributes, activities, products, or choices, as well as speech considered to be sarcastic, rude, or impudent (Eyberg et al., 2013). Commands are defined as statements directing children to perform a vocal or motor behavior, mental or internal action, or unobservable action (e.g., think, decide) that may be direct or indirect (Eyberg et al., 2013). Negative talks are broadly considered to characterize harsh parenting during any condition, while commands during child-led play were characterized as negative parenting behaviors due to the parent being instructed during this task to let their child choose an activity and follow their child's lead in play. These negative parenting behaviors were summed and then divided by the total number of coded parent behaviors to create a proportion of negative parenting during the dyadic interaction task. Coders completed 20 hours of intensive training prior to coding and continued to meet regularly to maintain $80 \%$ inter-rater reliability. All coders were blind to participants' assessment wave and condition group. Reliability coding was completed on $20 \%(n=89)$ of study families and $84 \%$ inter-rater reliability was achieved. Of the 89 families coded for reliability, $30 \%(n=27)$ were also coded for consensus.

\section{Results}

\section{Data Analysis Plan}

The goal of the present study was to predict engagement and retention with a PCIT program for child-welfare involved families. The focus was on discerning whether attributes of the parent, including ability to self-regulate and perceptions of their child's and their own behavior, would predict engagement in some or all of the treatment in a sample already at highrisk for early program dropout. Further, we sought to investigate unique predictors of dropout at each stage of the program, as each involves different challenges and thus may require different skill sets. We implemented multinomial logistic regression (MLR) to examine which of these 
factors predicted dropout at various stages throughout treatment. MLR produces odds ratios for each parameter indicating whether higher scores predict greater or lesser odds of dropping out during a particular stage versus dropping out earlier, later, or completing the treatment. Our outcome variable was a four-level categorical variable indicating where in treatment an individual dropped out: before treatment (non-engagers), during the CDI phase, during the PDI phase, or completed treatment.

Figure 1 displays the conceptual models that guided our analyses. Both models included negative parenting proportion as a control variable to enable the observation of the effects of parent characteristics on treatment persistence independently of their potential effects on parenting. Each of these models was run several times, alternating the reference category to allow for the comparison of each attrition category to the other three.

FIGURE 1 HERE

\section{Preliminary Analyses}

Means, standard deviations, and bivariate correlations for the key predictors are displayed in Table 1. Of the total $N=120,41$ parents did not engage in treatment (34.5\%), 26 parents engaged in treatment but dropped out during CDI (21.7\%), 16 parents dropped out during PDI (13.3\%), and 37 completed treatment (30.8\%). Participants who dropped out during CDI attended 4.19 CDI sessions on average ( $\mathrm{SD}=3.30$ ). Participants who dropped out during PDI attended an average of 8.88 CDI sessions $(\mathrm{SD}=2.45)$ and 3.69 PDI sessions $(\mathrm{SD}=1.85)$. Participants who completed treatment attended an average of 8.59 CDI sessions ( $\mathrm{SD}=1.52)$ and 10.41 PDI sessions ( $\mathrm{SD}=2.42)$. On average, the change in parent RSA from baseline to the challenge (cleanup) task was moderately negative $(M=-0.16, S D=0.86)$, and scores ranged from 3.06 to 2.70 , with $54.7 \%$ of the sample showing a withdrawal response (negative change score), 
while a sizable proportion of parents posted RSA increases instead. In contrast, the average change in RSA from the resting baseline to the Social Engagement Task was moderately positive $(M=0.21, S D=0.81)$; scores ranged from -2.43 to 2.83 , with $61.3 \%$ of the sample showing an increase in RSA (positive change score). Thus on average, RSA increased during this task relative to baseline, which may be expected given the role of parasympathetic activation in facilitating social engagement during face-to-face interactions (Norman Wells et al., 2020; Skowron et al., 2013), though a number of parents in the sample displayed decreases in RSA scores instead.

\section{TABLE 1 HERE}

There were minimal missing data for some of the predictors, baseline RSA ( 3 cases), challenge RSA change (3 cases), social engagement RSA change (5 cases), SSRT (11 cases), emotional go/no-go (1 case), and PAT (1 case). The most common reason cases were missing was due to non-completion of the assessment tasks, or in a few cases, equipment malfunction. As the multinomial logistic regression models were run using full information maximum likelihood (FIML) estimation, missing data was accounted for and the full sample of 120 was retained. A few predictors (SSRT, percentage of false alarm responses to angry faces in the emotional go/nogo task, change in RSA from resting to the challenge task, and change in RSA from resting to the social engagement task) had cases that would be considered outliers based on the criteria of being more than $3 \mathrm{SD}$ above or below the mean. Rather than dropping the data, a winnowing procedure was used to adjust outliers to be equal to the value of $3 \mathrm{SD}$ above or below the mean. This allows for retaining information about parents who may have extreme scores, as would be expected in a high-risk sample, but limits the influence outliers may have in statistical analyses. 
ANOVAs were run to determine the extent to which sociodemographic values differed based on treatment engagement and dropout. Contrary to prior research, no relationships were observed between parents' income $(F(98)=0.22, p=.88)$, education level $(F(119)=2.10, p=.10)$, or household size $(F(119)=1.25, p=.29)$ and persistence; however, this may be expected in a highrisk sample with restricted variability in these domains. Further, we did not observe any relationships between parents' age $(F(119)=0.284, p=.83)$ or race/ethnicity $(F(118)=0.48, p=.69)$, or children's age $(F(119)=0.88, p=.45)$ and treatment persistence. Considering these null findings, and in line with our theoretical models and goals of the present study, the sociodemographic parameters were trimmed from our final models.

\section{Primary Analyses}

Estimates, standard errors, p-values, and odds ratios are displayed in Table 2 for the selfregulation model and in Table 3 for the social-cognitive processes model.

Pre-treatment dropout (non-engagement). Levels of observed negative parenting during the pre-treatment assessment were salient in predicting who would decline treatment in PCIT. In the self-regulation model, greater negative parenting predicted greater odds of non-engagement versus engaging in treatment and dropping out during the CDI phase $(O R=1.96, \beta=0.53, p=.025)$, and marginally versus dropping out in PDI $(O R=1.78, \beta=0.99, p=.078)$ or completing the intervention $(O R=1.57, \beta=0.55, p=.078)$. Similarly, in the social-cognitive processes model, greater observed negative parenting during the pre-treatment assessment predicted greater odds of non-engagement versus dropping out during either the CDI phase $(O R=1.71, \beta=0.56, p=.009)$ or PDI phase $(O R=1.94, \beta=0.50, p=.020)$.

In the self-regulation model, parents' RSA reactivity to the challenge task (i.e., toy cleanup) and the social engagement task also predicted who would decline treatment. Greater parent 
RSA withdrawal from baseline to the toy clean-up challenge task predicted increased odds of not engaging in PCIT versus dropping out during the CDI phase $(O R=2.63, \beta=0.77, p=.008)$, marginally versus dropping out during PDI $(O R=2.42, \beta=0.77, p=.066)$, or versus completing treatment $(O R=2.00, \beta=0.85, p=.020)$. Further, results also showed that greater RSA increases from baseline to the social engagement task predicted greater odds of non-engagement versus dropping out during the CDI phase $(O R=2.32, \beta=0.67, p=.029)$ or the PDI phase $(O R=3.10$, $\beta=0.99, p<.001)$, and marginally versus completing treatment $(O R=1.83, \beta=0.55, p=.065)$.

In the social-cognitive processes model, parents' attributions on the PAT also appeared salient for predicting who would decline treatment. Parents who perceived that children have greater responsibility and control in shaping interaction dynamics had greater odds of not engaging in treatment versus dropping out during PDI $(O R=1.91, \beta=0.49, p=.022)$ or completing treatment $(O R=1.61, \beta=0.49, p=027)$.

CDI dropout. Parents' elevated threat sensitivity, measured as a greater percentage of "false alarm" responses to neutral faces during the angry condition, was a significant predictor of dropout during the CDI phase of treatment. Parents who more frequently erred in perceiving anger in neutral facial expressions had greater odds of dropping out during the CDI phase of PCIT versus non-engagement $(O R=2.00, \beta=0.72, p<.001)$, dropping out later during PDI $(O R=1.87, \beta=0.53, p=.008)$, or completing treatment $(O R=2.56, \beta=0.81, p<.001)$.

PDI dropout. Parents who perceived their children as being more harshly controlling toward them had greater odds of dropping out during the PDI phase versus non-engagement $(O R=2.36, \beta=0.65, p=.004)$, dropping out earlier during $\mathrm{CDI}(O R=2.16, \beta=0.65, p=.004)$, or completing treatment $(O R=1.76, \beta=0.79, p=.017)$. 
Treatment completion. Parents'self-reported readiness for change scores significantly predicted treatment completion. Specifically, parents who reported greater readiness to change on the REDI questionnaire had greater odds completing the intervention versus treatment nonengagers $(O R=1.73, \beta=0.57, p=.013)$.

\section{TABLE 2 HERE}

TABLE 3 HERE

\section{Discussion}

This study is the first to report on aspects of parents' social-cognitive and self-regulatory processes that predict engagement and attrition timing in PCIT amongst a sample of child welfare-involved families. Additionally, through the use of a novel multi-category treatment engagement variable, this study revealed unique predictors of PCIT engagement and timing of attrition. Findings lend support to the prospect that malleable aspects of parents' functioning, such as quality of parenting, child attributions, attentional biases to anger, and parasympathetically-mediated cardiac control (i.e., RSA), predict engagement and attrition in PCIT among child welfare-involved parents. As such, results of this study highlight plausible new targets of intervention that may promote treatment engagement and retention in these highrisk families. Below, we outline the significant predictors of family engagement and dropout from PCIT at four stages: pre-treatment (non-engagement), Child-Directed Interaction (CDI), Parent-Directed Interaction (PDI), and treatment completion.

\section{Treatment Non-Engagement}

In the current study, $36 \%$ of families randomized to the intervention condition declined to engage in treatment. Findings indicate that observed negative parenting and perceptions of children as more in control and responsible for the outcomes of adult-child interactions were 
both salient for predicting non-engagement. Parents who engaged in more negative (i.e., harsh, controlling) parenting during the preintervention assessment were less likely to accept the invitation to engage in treatment at all. Likewise, parents who perceived children as more in control and responsible for the outcome of adult-child exchanges relative to adults also were more likely to decline treatment. These findings are in line with other evidence suggesting that parental attributions are important in determining engagement in family-focused interventions, specifically with high-risk, low-income families (Mattek et al., 2016). If parents believe that they have little influence over their child's negative behavior, they may be less likely to engage in parenting-focused interventions such as PCIT, which contradict those perceptions (Mattek et al., 2016). In line with this idea, prior research on family-focused intervention has evidenced higher attrition rates for parents who believe that they have less control over their child's behavior (Mattek et al., 2016; Miller \& Prinz, 2003), whereas parents who perceive their own behavior as the cause of or contributor to their child's problem behavior (or within the parent's control) are more likely to complete treatment (Peters, Calam, \& Harrington, 2005). The contrast between non-engagers and treatment completers suggests that parents' locus of control may be an important factor in the decision whether or not to engage in PCIT. Parents who do not perceive adults as more responsible in the context of interactions with a child may recognize a disconnect between the way they parent and the fundamental tenants of evidence-based parenting interventions such as PCIT, which necessitate parent engagement and behavior change along with child behavior change as necessary components of treatment. In such cases, parents may believe that individual child-focused interventions are more suitable for their family needs, given their views that children are more responsible for their own behavior and for the outcomes of their interactions with parents as well. Along these lines, it is also possible that these parents hold 
beliefs about parenting and child development that are not well aligned with PCIT's core principles, and may further hold beliefs that authoritarian parenting is acceptable and perhaps even preferred for ensuring child compliance.

In addition to displaying negative parenting during interactions with their child, parents who declined treatment also showed greater RSA withdrawal to the challenging joint clean-up task and RSA activation to the prosocial engagement task. The fact that greater RSA withdrawal during the clean-up task with their child, taken together with greater harsh control parenting, predicted increased likelihood of declining treatment suggests that these parents may experience elevated stress reactivity in disciplinary contexts. In contrast to the social engagement task, the toy clean-up challenge task employed in this study is generally unpleasant for children, and evokes negative emotional responses from the child (e.g., resisting, complaining), while the task requires that parents work to gain their child's compliance to clean up a roomful of scattered toys. Prior research with CM families has shown that decreases in RSA during parent-child interactions are followed by increases in harsh, negative parenting among physically abusive parents (Skowron et al., 2013). Considering that parents who were more likely to forego treatment also displayed greater negative parenting, we may be observing a similar pattern among treatment non-engagers. Parents with these characteristics may have found the prospect of engaging in PCIT to be overwhelming, prompting greater likelihood of non-engagement.

The social engagement task utilized in this study was a prosocial task that prompted gentle physical contact and face-to-face engagement between parent and child. The finding of greater RSA activation among non-engaging parents contradicted our predictions and runs counter to some prior research that documents higher RSA in other warm prosocial parent-child interaction contexts (e.g., Augustine \& Leerkes, 2019; Smith et al., 2016). It is important to note 
that the social engagement task employed in this study was highly structured and further, that parenting behavior was not coded during this task. Therefore it is possible that treatment nonengaging parents behaved in qualitatively different ways with their child than did PCIT engaging parents (i.e., more negative, less engaged, and so forth). Alternately, the non-engaging parents, who viewed children as more responsible for the success of parent-child interactions, may have displayed increased RSA during the task because they felt less responsible for the success of the interactions with their children. Were these parents generally more physiologically reactive to their children than the PCIT-engaging parents, and thus displayed greater physiological calm because their children were pleasant interactive partners, or because the task was so highly structured, unlike the clean-up task? Alternately, were RSA increases helping to compensate for possible sympathetically-mediated increases in the arousal levels of these non-engaging parents (i.e., Gatzke-Kopp, Benson, Ryan, \& Ram, 2020)? Comparatively, parents who engaged in treatment and dropped out showed relatively lower RSA in this context, likely indicating the need to mobilize more attentional resources to engage with their child during the interactions required in the task. This finding raises important questions and directions for future research aimed at better understanding the coupling of RSA reactivity and parenting behavior, and the contributions of sympathetic nervous system responding during prosocial parent-child activities in maltreatment parents.

Taken together, this constellation of predictive factors (negative parenting, greater child control attributions, RSA withdrawal to challenge, and RSA increases to social engagement) provide rich new insights into which child welfare-involved parents are more likely to decline a parenting-focused treatment. Given that similar risk factors are observed in parents at risk for perpetrating $\mathrm{CM}$, these findings are especially notable. Parents who are most at risk for 
perpetrating maltreatment are also among the least likely to voluntarily engage in a treatment shown to be effective at reducing CM recidivism (e.g., Kennedy, Kim, Tripodi, Brown, \& Gowdy, 2016). Maltreating parents show a pattern of harsh parenting and threat-sensitive attributions in which children are believed to be the cause of dysfunctional interactions, which is accompanied by activation of parent physiological stress response systems during difficult child behavior (i.e., increased cortisol; Lin, Bugental, Turek, Martorell, \& Olster, 2002; increases in heart rate; Bugental et al., 1993, Bugental, Lewis, Lin, Lyon, \& Kopeikin, 1999; Lin et al., 2002; increases in electrodermal activity; Bugental \& Cortez, 1988; and decreases in RSA; Norman Wells et al., 2020). An important avenue for future research will be to quantify observed parenting behaviors among parents at risk for non-engagement. Specifically, we may want to know whether RSA increases are associated with low dyadic engagement processes (e.g., less verbalization, lower dyadic synchrony, and more relationship ruptures) from parents, or whether RSA decreases are accompanied by other signs of stress, and whether they drive increases in aversive parenting. Greater understanding into the role of sympathetic input into cardiac responses that support adaptive parenting is also needed.

\section{Attrition during CDI}

Among families that engaged in the intervention, 22\% dropped out at some point during the CDI phase of treatment, during which parents are taught strategies for interacting with their children in warm, positive ways and sensitively reinforcing children's positive behavior. In CDI, parents learn to use specific praise for positive behavior, describe and reflect their children's behavior and speech, and show enthusiasm and enjoyment of their time together. During CDI sessions, parents become more attuned with their child's behavior, emotions, and thoughts, which in turn could promote increased ability to understand and respond positively to their 
child's needs (Eyberg et al., 2001). Though interactions are mainly positive during this phase of treatment, parents are asked to follow their child's lead in the play, and to relinquish some control in doing so. Parents are also asked to ignore minor child misbehavior. As such, there are some qualities that the parent brings to the room that could make these activities feel more challenging, and increase the odds of dropout during this phase.

Findings from this study suggest that one such quality may be a threat-related bias toward perceiving anger in facial expressions where none is present. Parents who were more likely to dropout in this CDI phase of treatment were also more likely to see anger in neutral facial expressions in the emotional go/no-go task, relative to other conditions (i.e., not engage, persist to PDI and then dropout, or to complete treatment). Parents with a bias toward perceiving anger may find it more difficult to recognize their children's positive emotional expressions, and acknowledge when their children are behaving in positive, prosocial ways. Such perceptual biases toward angry facial cues also may make it more challenging for parents to ignore their children's minor misbehavior, and respond accurately to positive or neutral cues from their child. Likewise, these more threat-sensitive parents may find it more difficult to relinquish control during the CDI phase's child-led play. It is well established that maltreating parents are more likely to view themselves as victims of their child's misbehavior, and perceive such behavior as threatening and intentional (Bugental, 2009; Bugental, Blue, \& Lewis, 1990; Bugental \& Happaney, 2004; Martorell \& Bugental, 2006). As such, relinquishing control to the child may cause anxiety for parents who hold threat-sensitive attentional biases in which they perceive anger where none is present, prompting increased likelihood of dropout during the child-led phase of treatment. 
Although no research has yet examined general threat sensitivity among maltreating parents using methods we have employed here, prior studies have found that in maltreating families, children who were abused or neglected show a bias wherein they respond more quickly to angry facial expressions (Pollak \& Sinha, 2002). This bias is interpreted as reflecting a greater vigilance toward aggressive, threatening emotions, arising from experiences with perpetrators of maltreatment and enabling them to more quickly identify threat in social interactions (Masten et al., 2008; Pollak \& Sinha, 2002). It is also possible that parents in maltreating families possess related biases, a tendency to perceive anger in neutral facial displays more readily, fueling a heightened sense of threat where there may be none, and lash out in harsh ways as a result. It is possible these findings converge to mark a familial vulnerability or a source of socialization of threat sensitivity from parent to child. This idea is supported in part by prior work that suggests that in families where parents experience symptoms of internalizing psychopathology, both parents and children exhibit threat biases (Bar-Haim et al., 2007; Morales et al., 2017, Morales, Pérez-Edgar, \& Buss, 2015).

\section{Attrition during PDI}

Thirteen percent (13\%) of families dropped out during the PDI phase of treatment during which sessions focus on helping parents building safe, effective discipline skills to use with their children. In this phase, parents are prompted to deliver direct commands and offer praise for child compliance or apply a consistent time-out procedure for handling child misbehavior. As such, the ability to maintain a calm authority during this phase of treatment is crucial. There are characteristics of both the parent and the parent-child relationship that may make this phase difficult to master and increase risk for dropout. For instance, parents may experience challenges 
with this phase of treatment if they are typically lax in their discipline, allowing misbehavior to continue, or making threats of consequences without following through.

In the current study, we discovered that parents who perceived their children as more harshly controlling had greater odds of dropping out during the PDI phase than non-engagement, dropping out during CDI, or completing treatment. This finding is in line with prior research identifying negative attributions about a child as a propagating factor in the perpetration of child maltreatment (Azar \& Twentyman, 1986; Crouch et al., 2015; Larrance \& Twentyman, 1983). Additionally, viewing children's misbehavior as intentionally provocative and due to negative dispositional traits may lead parents to believe they are unable to affect change in their child's behavior or successfully interrupt coercive processes, and thus drop out from treatment as a result (Mattek et al., 2016). Alternately, parents may resist therapists' efforts to modify their parenting behaviors and feel little confidence that therapy can modify their child's problem behavior. In these contexts, such beliefs may lead a parent to react defensively to children's behavior or react with anger in retaliation (Bugental, 2009). When applied to the PDI phase of treatment, these parents may have a greater amount of difficulty adhering to guidance provided by PCIT therapists and following through on children's non-compliance with parental directives in a calm and consistent manner to achieve child compliance.

\section{Completing Treatment}

Approximately one-third (29\%) of parents completed a full course of PCIT, in line with other studies of child welfare-involved families' engagement in family-based interventions (e.g., Lanier et al., 2011). Perhaps not surprisingly, child welfare parents who posted higher scores on the readiness to change scale were more likely to complete the PCIT intervention, relative to non-engaging parents. Items on this scale are meant to assess motivation to engage in a parenting 
intervention and for improving one's parenting skills (i.e., recognizing that there is a problem, wanting to change the problem, and believing that a parenting intervention could be effective for change). Similarly, research on addiction treatment outcomes has documented that individuals who perceive a problem and have the motivation to change are the most likely to institute behavior change when provided adequate means to achieve that goal (Mullins et al., 2004). Prior studies have shown that motivation enhancement supplements can be effective for improving persistence in PCIT among child welfare families for whom readiness for change was low, but may be unnecessary or even detrimental for those who are already highly motivated change (e.g., Chaffin, Funderbunk, Bard, Valle, \& Gurwitch, 2011; Webb et al., 2017). Findings such as these underscore the central importance of positive beliefs about making changes in parenting and the parent-child relationship for addressing the problem of attrition among these higher-risk families.

\section{Clinical Implications}

PCIT is one of few effective interventions for reducing CM recidivism among child welfare-involved families (Euser et al., 2015). As such, understanding factors that predict PCIT treatment engagement and retention is crucial for the well-being of children and reducing the burden of CM on the public health system. Child abuse and neglect often occur in contexts where parents are unresponsive to their child's needs and behavior, relationship quality is low, resulting in a weakened caregiving relationship between parent and child (Stith et al., 2009; Toth \& Cicchetti, 2013). The skills taught in PCIT help to reduce such negative interactional patterns by providing parents with relationship enhancement tools in CDI that support and strengthen the caregiving relationship and buffer against future episodes of CM (Chaffin et al., 2004; Hakman et al., 2009). Further, maltreatment often occurs during disciplinary exchanges, during which escalations in harsh parenting and negative child behavior lead to risk for harm (Ateah \& 
Durrant, 2005; Crouch \& Behl, 2001; Riggins-Caspers, Cadoret, Knutson, \& Langbehn, 2003; Straus, 2001). During PCIT's PDI phase, parents learn and practice tools for effective discipline that obtain child compliance without escalating into coercive cycles and abuse.

The rates of engagement in parent- and family-focused interventions are lower among child welfare-involved families than in other community samples. However, findings of this study shed exciting new light on potentially modifiable barriers to treatment engagement among child welfare-involved families. Of particular note, parents who declined to engage in PCIT at all were those who engaged in the highest levels of negative parenting at intake. As participation in PCIT has been shown to achieve marked declines in negative parenting (Hakman et al., 2009), parents who may benefit most (i.e., those with higher levels of negative parenting and thus greater potential for change) may be least inclined to voluntarily enter into treatment. Together with observations of negative parenting, patterns of parasympathetic nervous system responding also were salient for predicting those families who did not engage. Taken together, the results of this study suggest that although relatively calm in low-stress contexts, parents who were both physiologically aroused during a challenging disciplinary task and displayed greater negativity with their child were at greater risk for treatment non-engagement. As such, the utility of brief intervention components that target parents' physiological reactivity and help scaffold positive parenting could be examined to determine whether they support increased readiness for treatment engagement. For instance, brief mindfulness meditation has been shown to induce physiological calm, specifically in terms of increased RSA (Ditto, Eclache, \& Goldman, 2006), and mindfulness training has been identified as a support for positive parenting practices (Duncan, Coatsworth, \& Greenberg, 2009; Singh et al., 2010, 2019). 
Many of the strongest predictors identified in the current study identified whether child welfare-involved parents would choose to begin PCIT treatment. Arguably, given that even some engagement in PCIT can be effective in promoting positive parenting, (e.g., Lieneman et al., 2019), findings from the current study lend support for the use of physiological and socialcognitive screening measures to identify which parents may need additional supports to engage in treatment. Given that key predictors of treatment non-engagement are also important risk factors for child maltreatment perpetration, the current findings may also lend support for revisiting policies that mandate engagement in family-focused interventions for child welfareinvolved families, in order to lower risk for re-abuse and extend the reach of the program to more child welfare involved families in need of services. With the growing accessibility to ambulatory devices that can quantify heart rate variability among other physiological and behavioral measures, identification of families at-risk for non-engagement may be improved (Youngstrom \& De Los Reyes, 2015).

Once engaged in treatment, several factors were shown to promote family persistence in PCIT. Evidence from this study suggests that a perceptual bias toward seeing angry facial cues where none exist increases the risk for dropout from the phase of treatment focused on strengthening a parent's warm relationship with their child. Following the transition into PDI phase work focused on developing safe, effective discipline strategies, our findings suggest that parents who hold more positive attributions about their children are more likely to persist in PCIT. Though PCIT is a behavioral parent training program, these findings suggest that parents' social cognitions about their children may also be potentially critical targets of intervention early in treatment. Future research is needed ascertain whether PCIT is capable of softening parents' harsh, threat-sensitive attributions of their children behavior in the service of retaining more 
families in PCIT through to completion. Findings also lend support to the utility of screening parents for readiness for change, and engaging those families with low readiness in motivational enhancement sessions before the start of treatment, as observed by others (Chaffin et al., 2009), in order to promote greater likelihood of treatment completion. However, more research is needed to examine the specific efficacy of ME sessions in promoting treatment engagement and readiness for change, as neither were directly tested in the current study.

\section{Limitations}

The current study provides valuable insight into the factors that predict attrition from PCIT at different stages of the intervention for families who are involved in the child welfare system. However, this study did not investigate all modifiable parent factors that could contribute to attrition, and important questions remain for future research, for example, examining the impact of parent mental health (e.g., depressive symptoms, anxiety symptoms, antisocial traits, abuse history), or interactions between social-cognitive and self-regulatory predictors (e.g., parent RSA and negative behavior). More research will be needed to replicate these findings and examine their relevance to more diverse samples of families, including families from different geographical regions, across urban and rural settings. In addition, as the study focused on engagement and attrition from PCIT, which has unique features such as using in-the-moment live coaching, more research is needed to determine whether the malleable factors we have identified in the current study affect attrition from other evidence-based, familyfocused interventions. It would also be useful to replicate this study using a larger sample size in order to detect smaller effects among parent factors and treatment retention.

Important questions remain regarding the relations between child maltreatment risk, biomarkers of self-regulation and social-cognitive processes, and treatment retention among 
parents. We believe that the risk factors identified here for attrition among child welfareinvolved parents, including parasympathetically-mediated cardiac control, threat-related cognitive biases, and negative parent attributions are also viable intervention targets for PCIT (Nekkanti et al., 2020; Skowron, 2015). In other words, continued engagement in PCIT is hypothesized to have positive effects on these malleable parent characteristics and mediate the effects of the intervention on parenting outcomes and CM recidivism (Skowron \& Funderburk, in preparation). If confirmed, such findings would provide credible support for individuallytailored approaches to mandating treatment among child welfare-involved families who are most at risk for non-engagement or treatment attrition, knowing that these families may have the most to gain from completing the intervention but the greatest difficulty staying engaged. Follow-up work will further elucidate mechanisms supporting both continued engagement and improvements in parenting behavior throughout PCIT treatment.

\section{Conclusions}

Preventing child maltreatment recidivism is a high priority public health initiative and successful treatment with PCIT is both an effective and cost-effective solution. Developing strategies for increasing engagement of maltreating families in PCIT remains a crucial task. Findings from the current study suggest that modifiable characteristics of maltreating parents may pose barriers to treatment engagement, and suggest avenues for enhancement of the PCIT intervention to suit the needs of high-risk child welfare-involved families to reduce barriers and promote treatment persistence, ultimately leading to better outcomes for parents and children. 


\section{References}

Ablow, J. C., Marks, A. K., Shirley Feldman, S., \& Huffman, L. C. (2013). Associations between first-time expectant women's representations of attachment and their physiological reactivity to infant cry. Child Development, 84(4), 1373-1391. https://doi.org/10.1111/cdev.12135

Aos, S., Lieb, R., Mayfield, J., Miller, M., \& Pennucci, A. (2004). Benefits and costs of prevention and early intervention programs for youth. Washington State Institute for Public Policy.

Aron, A. R., Robbins, T. W., \& Poldrack, R. A. (2004). Inhibition and the right inferior frontal cortex. Trends in Cognitive Sciences, 8(4), 170-177. https://doi.org/10.1016/j.tics.2004.02.010

Ateah, C. A., \& Durrant, J. E. (2005). Maternal use of physical punishment in response to child misbehavior: Implications for child abuse prevention. Child Abuse \& Neglect, 29(2), 169-185. https://doi.org/10.1016/j.chiabu.2004.10.010

Augustine, M. E., \& Leerkes, E. M. (2019). Associations between maternal physiology and maternal sensitivity vary depending on infant distress and emotion context. Journal of Family Psychology, 33(4), 412-421. https://doi.org/10.1037/fam0000538

Azar, S., \& Twentyman, C. (1986). Cognitive-behavioral perspectives on the assessment and treatment of child abuse. In P. C. Kendall (Ed.), Advances in cognitive-behavioral research and therapy (Vol. 5, pp. 237-267). Academic Press.

Bagner, D. M., \& Graziano, P. A. (2013). Barriers to success in parent training for young children with developmental delay: The role of cumulative risk. Behavior Modification, 37(3), 356-377. https://doi.org/10.1177/0145445512465307 
Bagner, D. M., Sheinkopf, S. J., Miller-Loncar, C. L., Vohr, B. R., Hinckley, M., Eyberg, S. M., \& Lester, B. M. (2009). Parent-Child Interaction Therapy for children born premature: A case study and illustration of vagal tone as a physiological measure of treatment outcome. Cognitive and Behavioral Practice, 16(4), 468-477.

https://doi.org/10.1016/j.cbpra.2009.05.002

Bar-Haim, Y., Lamy, D., Pergamin, L., Bakermans-Kranenburg, M. J., \& van IJzendoorn, M. H. (2007). Threat-related attentional bias in anxious and nonanxious individuals: A metaanalytic study. Psychological Bulletin, 133(1), 1-24. https://doi.org/10.1037/00332909.133.1.1

Beauchaine, T. P. (2015). Future directions in emotion dysregulation and youth psychopathology. Journal of Clinical Child \& Adolescent Psychology, 44(5), 875-896. https://doi.org/10.1080/15374416.2015.1038827

Beauchaine, T. P., Bell, Z., Knapton, E., McDonough-Caplan, H., Shader, T., \& Zisner, A. (2019). Respiratory sinus arrhythmia reactivity across empirically based structural dimensions of psychopathology: A meta-analysis. Psychophysiology, 56(5), e13329. https://doi.org/10.1111/psyp.13329

Beckerman, M., van Berkel, S. R., Mesman, J., \& Alink, L. R. A. (2017). The role of negative parental attributions in the associations between daily stressors, maltreatment history, and harsh and abusive discipline. Child Abuse \& Neglect, 64, 109-116. https://doi.org/10.1016/j.chiabu.2016.12.015

Beckerman, M., van Berkel, S. R., Mesman, J., Huffmeijer, R., \& Alink, L. R. A. (2019). Are negative parental attributions predicted by situational stress? From a theoretical 
assumption toward an experimental answer. Child Maltreatment, 25(3), 352-362. https://doi.org/10.1177/1077559519879760

Benjamin, L. S., Rothweiler, J. C., \& Critchfield, K. L. (2006). The use of Structural Analysis of Social Behavior (SASB) as an assessment tool. Annual Review of Clinical Psychology, 2(1), 83-109. https://doi.org/10.1146/annurev.clinpsy.2.022305.095337

Bradley, E. J., \& Peters, R. D. (1991). Physically abusive and nonabusive mothers' perceptions of parenting and child behavior. American Journal of Orthopsychiatry, 61(3), 455-460. https://doi.org/10.1037/h0079263

Bugental, D. (2009). Predicting and preventing child maltreatment: A biocognitive transactional approach. In A. Sameroff (Ed.), The transactional model of development: How children and contexts shape each other (pp. 97-115). American Psychological Association. https://doi.org/10.1037/11877-006

Bugental, D. B., Blue, J., \& Cruzcosa, M. (1989). Perceived control over caregiving outcomes: Implications for child abuse. Developmental Psychology, 25(4), 532-539. https://doi.org/10.1037/0012-1649.25.4.532

Bugental, D. B., Blue, J., \& Lewis, J. (1990). Caregiver beliefs and dysphoric affect directed to difficult children. Developmental Psychology, 26(4), 631-638. https://doi.org/10.1037/0012-1649.26.4.631

Bugental, D. B. (1987). Attributions as moderator variables within social interactional systems. Journal of Social and Clinical Psychology, 5(4), 469-484. https://doi.org/10.1521/jscp.1987.5.4.469 
Bugental, D. B., \& Happaney, K. (2004). Predicting infant maltreatment in low-income families: The interactive effects of maternal attributions and child status at birth. Developmental Psychology, 40(2), 234-243. https://doi.org/10.1037/0012-1649.40.2.234

Burns, B. J., Phillips, S. D., Wagner, H. R., Barth, R. P., Kolko, D. J., Campbell, Y., \& Landsverk, J. (2004). Mental health need and access to mental health services by youths involved with child welfare: A national survey. Journal of the American Academy of Child \& Adolescent Psychiatry, 43(8), 960-970. https://doi.org/10.1097/01.chi.0000127590.95585.65

Capage, L. C., Bennett, G. M., \& McNeil, C. B. (2001). A comparison between African American and Caucasian children referred for treatment of disruptive behavior disorders. Child \& Family Behavior Therapy, 23(1), 1-14. https://doi.org/10.1300/J019v23n01_01

Chaffin, M., Funderburk, B., Bard, D., Valle, L. A., \& Gurwitch, R. (2011). A combined motivation and Parent-Child Interaction Therapy package reduces child welfare recidivism in a randomized dismantling field trial. Journal of Consulting and Clinical Psychology, 79(1), 84-95. https://doi.org/10.1037/a0021227

Chaffin, M., Silovsky, J. F., Funderburk, B., Valle, L. A., Brestan, E. V., Balachova, T., Jackson, S., Lensgraf, J., \& Bonner, B. L. (2004). Parent-Child Interaction Therapy with physically abusive parents: efficacy for reducing future abuse reports. Journal of Consulting and Clinical Psychology, 72(3), 500-510. https://doi.org/10.1037/0022006X.72.3.500

Chaffin, M., Valle, L. A., Funderburk, B., Gurwitch, R., Silovsky, J., Bard, D., McCoy, C., \& Kees, M. (2009). A motivational intervention can improve retention in PCIT for low- 
motivation child welfare clients. Child Maltreatment, 14(4), 356-368. https://doi.org/10.1177/1077559509332263

Chen, M., \& Johnston, C. (2007). Maternal inattention and impulsivity and parenting behaviors. Journal of Clinical Child \& Adolescent Psychology, 36(3), 455-468. https://doi.org/10.1080/15374410701448570

Comer, J. S., Furr, J. M., Miguel, E. M., Cooper-Vince, C. E., Carpenter, A. L., Elkins, R. M., Kerns, C. E., Cornacchio, D., Chou, T., Coxe, S., DeSerisy, M., Sanchez, A. L., Golik, A., Martin, J., Myers, K. M., \& Chase, R. (2017). Remotely delivering real-time parent training to the home: An initial randomized trial of Internet-Delivered Parent-Child Interaction Therapy (I-PCIT). Journal of Consulting and Clinical Psychology, 85(9), 909-917. https://doi.org/10.1037/ccp0000230

Crandall, A., Deater-Deckard, K., \& Riley, A. W. (2015). Maternal emotion and cognitive control capacities and parenting: A conceptual framework. Developmental Review, 36, 105-126. https://doi.org/10.1016/j.dr.2015.01.004

Creaven, A. M., Skowron, E. A., Hughes, B. M., Howard, S., \& Loken, E. (2014). Dyadic concordance in mother and preschooler resting cardiovascular function varies by risk status: Cardiovascular concordance in mother-child dyads. Developmental Psychobiology, 56(1), 142-152. https://doi.org/10.1002/dev.21098

Crouch, J. L., \& Behl, L. E. (2001). Relationships among parental beliefs in corporal punishment, reported stress, and physical child abuse potential. Child Abuse \& Neglect, 25(3), 413-419. https://doi.org/10.1016/S0145-2134(00)00256-8

Crouch, J. L., Hiraoka, R., McCanne, T. R., Reo, G., Wagner, M. F., Krauss, A., Milner, J. S., \& Skowronski, J. J. (2015). Heart rate and heart rate variability in parents at risk for child 
physical abuse. Journal of Interpersonal Violence, 33(10), 1629-1652.

https://doi.org/10.1177/0886260515619169

Danko, C. M., Garbacz, L. L., \& Budd, K. S. (2016). Outcomes of Parent-Child Interaction Therapy in an urban community clinic: A comparison of treatment completers and dropouts. Children and Youth Services Review, 60, 42-51. https://doi.org/10.1016/j.childyouth.2015.11.007

Deater-Deckard, K., Wang, Z., Chen, N., \& Bell, M. A. (2012). Maternal executive function, harsh parenting, and child conduct problems. Journal of Child Psychology and Psychiatry, 53(10), 1084-1091. https://doi.org/10.1111/j.1469-7610.2012.02582.x

Ditto, B., Eclache, M., \& Goldman, N. (2006). Short-term autonomic and cardiovascular effects of mindfulness body scan meditation. Annals of Behavioral Medicine, 32(3), 227-234. https://doi.org/10.1207/s15324796abm3203_9

Duncan, L. G., Coatsworth, J. D., \& Greenberg, M. T. (2009). A model of mindful parenting: Implications for parent-child relationships and prevention research. Clinical Child and Family Psychology Review, 12, 255-270.

Euser, S., Alink, L. R., Stoltenborgh, M., Bakermans-Kranenburg, M. J., \& van IJzendoorn, M. H. (2015). A gloomy picture: A meta-analysis of randomized controlled trials reveals disappointing effectiveness of programs aiming at preventing child maltreatment. $B M C$ Public Health, 15(1), 1068. https://doi.org/10.1186/s12889-015-2387-9

Eyberg, S. (1988). Parent-Child Interaction Therapy: Integration of traditional and behavioral concerns. Child \& Family Behavior Therapy, 10(1), 33-46. https://doi.org/10.1300/J019v10n01_04 
Eyberg, S. M., Boggs, S. R., \& Algina, J. (1995). Parent-Child Interaction Therapy: A psychosocial model for the treatment of young children with conduct problem behavior and their families. Psychopharmacology Bulletin, 31(1), 83-91.

Eyberg, S. M., \& Funderburk, B. (2011). Parent-Child Interaction Therapy protocol. PCIT International.

Eyberg, S. M., Nelson, M. M., Ginn, N. C., Bhuiyan, N., \& Boggs, S. R. (2013). Dyadic ParentChild Interaction Coding System (DPICS) comprehensive manual for research and training (4th Edition). PCIT International.

Eyberg, Sheila M., Funderburk, B. W., Hembree-Kigin, T. L., McNeil, C. B., Querido, J. G., \& Hood, K. K. (2001). Parent-Child Interaction Therapy with behavior problem children: One and two year maintenance of treatment effects in the family. Child \& Family Behavior Therapy, 23(4), 1-20. https://doi.org/10.1300/J019v23n04_01

Fernandez, M. A., \& Eyberg, S. M. (2009). Predicting treatment and follow-up attrition in Parent-Child Interaction Therapy. Journal of Abnormal Child Psychology, 37(3), 431441. https://doi.org/10.1007/s10802-008-9281-1

Fontaine, D., \& Nolin, P. (2012). Personality disorders in a sample of parents accused of physical abuse or neglect. Journal of Family Violence, 27(1), 23-31. https://doi.org/10.1007/s10896-011-9403-3

Weismer Fries, A. B., Ziegler, T. E., Kurian, J. R., Jacoris, S., \& Pollak, S. D. (2005). Early experience in humans is associated with changes in neuropeptides critical for regulating social behavior. Proceedings of the National Academy of Sciences, 102(47), 1723717240. https://doi.org/10.1073/pnas.0504767102 
Funderburk, B. W., \& Eyberg, S. (2010). Parent-Child Interaction Therapy. In J. C. Norcross, G. R. VandenBos, \& D. K. Freedheim (Eds.), History of psychotherapy: Continuity and change (pp. 415-420). American Psychological Association.

Gatzke-Kopp, L. M., Benson, L., Ryan, P. J., \& Ram, N. (2020). Cortical and affective regulation of autonomic coordination. Psychophysiology, 57. Advance Online Publication. https://doi.org/10.1111/psyp.13544

Gopalan, G., Bannon, W., Dean-Assael, K., Fuss, A., Gardner, L., LaBarbera, B., \& McKay, M. (2011). Multiple family groups: An engaging intervention for child welfare-involved families. Child Welfare, 90(4), 135-156.

Graziano, P. A., Bagner, D. M., Sheinkopf, S. J., Vohr, B. R., \& Lester, B. M. (2012). Evidencebased intervention for young children born premature: Preliminary evidence for associated changes in physiological regulation. Infant Behavior and Development, 35(3), 417-428. https://doi.org/10.1016/j.infbeh.2012.04.001

Gross, D., Belcher, H. M. E., Budhathoki, C., Ofonedu, M. E., \& Uveges, M. K. (2018). Does parent training format affect treatment engagement? A randomized study of families at social risk. Journal of Child and Family Studies, 27(5), 1579-1593. https://doi.org/10.1007/s10826-017-0984-1

Hakman, M., Chaffin, M., Funderburk, B., \& Silovsky, J. F. (2009). Change trajectories for parent-child interaction sequences during Parent-Child Interaction Therapy for child physical abuse. Child Abuse \& Neglect, 33(7), 461-470.

https://doi.org/10.1016/j.chiabu.2008.08.003 
Hastings, P. D., \& Rubin, K. H. (1999). Predicting mothers' beliefs about preschool-aged children's social behavior: Evidence for maternal attitudes moderating child effects. Child Development, 70(3), 722-741. https://doi.org/10.1111/1467-8624.00052

Herschell, A. D., \& McNeil, C. B. (2005). Parent-child interaction therapy with physically abusive families. In J. M. Briesmeister \& C. E. Schaefer (Eds.), Handbook of parent training: Helping parents prevent and solve problem behaviors (pp. 234-267). John Wiley \& Sons, Inc.

Joosen, K. J., Mesman, J., Bakermans-Kranenburg, M. J., \& van IJzendoorn, M. H. (2013). Maternal overreactive sympathetic nervous system responses to repeated infant crying predicts risk for impulsive harsh discipline of infants. Child Maltreatment, 18(4), 252263. https://doi.org/10.1177/1077559513494762

Kazdin, A. E. (1996). Dropping out of child psychotherapy: Issues for research and implications for practice. Clinical Child Psychology and Psychiatry, 1(1), 133-156. https://doi.org/10.1177/1359104596011012

Kazdin, A. E., \& Mazurick, J. L. (1994). Dropping out of child psychotherapy: Distinguishing early and late dropouts over the course of treatment. Journal of Consulting and Clinical Psychology, 62(5), 1069-1074. https://doi.org/10.1037/0022-006X.62.5.1069

Kazdin, A. E., Mazurick, J. L., \& Bass, D. (1993). Risk for attrition in treatment of antisocial children and families. Journal of Clinical Child Psychology, 22(1), 2-16. https://doi.org/10.1207/s15374424jccp2201_1

Kennedy, S. C., Kim, J. S., Tripodi, S. J., Brown, S. M., \& Gowdy, G. (2016). Does ParentChild Interaction Therapy reduce future physical abuse? A meta-analysis. Research on Social Work Practice, 26(2), 147-156. https://doi.org/10.1177/1049731514543024 
Lanier, P., Kohl, P. L., Benz, J., Swinger, D., Moussette, P., \& Drake, B. (2011). Parent-Child Interaction Therapy in a community setting: Examining outcomes, attrition, and treatment setting. Research on Social Work Practice, 21(6), 689-698. https://doi.org/10.1177/1049731511406551

Larrance, D. T., \& Twentyman, C. T. (1983). Maternal attributions and child abuse. Journal of Abnormal Psychology, 92(4), 449-457. https://doi.org/10.1037/0021-843X.92.4.449

Leerkes, E. M., Su, J., Calkins, S. D., Supple, A. J., \& O’Brien, M. (2016). Pathways by which mothers' physiological arousal and regulation while caregiving predict sensitivity to infant distress. Journal of Family Psychology, 30(7), 769-779. https://doi.org/10.1037/fam0000185

Lieneman, C. C., Brabson, L. A., Highlander, A., Wallace, N. M., \& McNeil, C. B. (2017). Parent-Child Interaction Therapy: Current perspectives. Psychology Research and Behavior Management, 10, 239-256. https://doi.org/10.2147/PRBM.S91200

Lieneman, C. C., Quetsch, L. B., Theodorou, L. L., Newton, K. A., \& McNeil, C. B. (2019). Reconceptualizing attrition in Parent-Child Interaction Therapy: "Dropouts" demonstrate impressive improvements. Psychology Research and Behavior Management, 12, 543555. https://doi.org/10.2147/PRBM.S207370

Lorber, M. F., \& O’Leary, S. G. (2005). Mediated paths to overreactive discipline: Mothers' experienced emotion, appraisals, and physiological responses. Journal of Consulting and Clinical Psychology, 73(5), 972-981. https://doi.org/10.1037/0022-006X.73.5.972

Lunkenheimer, E., Tiberio, S. S., Skoranski, A. M., Buss, K. A., \& Cole, P. M. (2018). Parentchild coregulation of parasympathetic processes varies by social context and risk for psychopathology. Psychophysiology, 55(2). https://doi.org/10.1111/psyp.12985 
Lupien, S. J., McEwen, B. S., Gunnar, M. R., \& Heim, C. (2009). Effects of stress throughout the lifespan on the brain, behaviour and cognition. Nature Reviews Neuroscience, 10(6), 434-445. https://doi.org/10.1038/nrn2639

Martorell, G. A., \& Bugental, D. B. (2006). Maternal variations in stress reactivity: Implications for harsh parenting practices with very young children. Journal of Family Psychology, 20(4), 641-647. https://doi.org/10.1037/0893-3200.20.4.641

Masten, C. L., Guyer, A. E., Hodgdon, H. B., McClure, E. B., Charney, D. S., Ernst, M., Kaufman, J., Pine, D. S., \& Monk, C. S. (2008). Recognition of facial emotions among maltreated children with high rates of post-traumatic stress disorder. Child Abuse \& Neglect, 32(1), 139-153. https://doi.org/10.1016/j.chiabu.2007.09.006

Mattek, R. J., Harris, S. E., \& Fox, R. A. (2016). Predicting treatment success in child and parent therapy among families in poverty. The Journal of Genetic Psychology, 177(2), 44-54. https://doi.org/10.1080/00221325.2016.1147415

McCanne, T. R., \& Hagstrom, A. H. (1996). Physiological hyperreactivity to stressors in physical child abusers and individuals at risk for being physically abusive. Aggression and Violent Behavior, 1(4), 345-358. https://doi.org/10.1016/S1359-1789(96)00004-3

Miller, G. E., \& Prinz, R. J. (2003). Engagement of families in treatment for childhood conduct problems. Behavior Therapy, 34(4), 517-534. https://doi.org/10.1016/S00057894(03)80033-3

Morales, S., Brown, K. M., Taber-Thomas, B. C., LoBue, V., Buss, K. A., \& Pérez-Edgar, K. E. (2017). Maternal anxiety predicts attentional bias towards threat in infancy. Emotion, 17(5), 874-883. https://doi.org/10.1037/emo0000275 
Morales, S., Pérez-Edgar, K. E., \& Buss, K. A. (2015). Attention biases towards and away from threat mark the relation between early dysregulated fear and the later emergence of social withdrawal. Journal of Abnormal Child Psychology, 43(6), 1067-1078. https://doi.org/10.1007/s10802-014-9963-9

Mullins, S. M., Suarez, M., Ondersma, S. J., \& Page, M. C. (2004). The impact of motivational interviewing on substance abuse treatment retention: A randomized control trial of women involved with child welfare. Journal of Substance Abuse Treatment, 27(1), 5158. https://doi.org/10.1016/j.jsat.2004.03.010

Nekkanti, A. K., Jeffries, R., Scholtes, C. M., Shimomaeda, L., DeBow, K., Norman Wells, J., Lyons, E. R., Giuliano, R. J., Gutierrez, F. J., Woodlee, K. X., Funderburk, B. W., \& Skowron, E. A. (2020). Study protocol: The Coaching Alternative Parenting Strategies (CAPS) study of Parent-Child Interaction Therapy in child welfare families. Frontiers in Psychiatry, 11, 839. https://doi.org/10.3389/fpsyt.2020.00839

Nixon, R. D. V., Sweeney, L., Erickson, D. B., \& Touyz, S. W. (2003). Parent-Child Interaction Therapy: A comparison of standard and abbreviated treatments for oppositional defiant preschoolers. Journal of Consulting and Clinical Psychology, 71(2), 251-260. https://doi.org/10.1037/0022-006X.71.2.251

Nixon, R. D. V., Sweeney, L., Erickson, D. B., \& Touyz, S. W. (2004). Parent-Child Interaction Therapy: One- and two-year follow-up of standard and abbreviated treatments for oppositional preschoolers. Journal of Abnormal Child Psychology, 32(3), 263-271. https://doi.org/10.1023/B:JACP.0000026140.60558.05

Norman Wells, J., Skowron, E. A., Scholtes, C. M., \& DeGarmo, D. S. (2020). Differential physiological sensitivity to child compliance behaviors in abusing, neglectful, and non- 
maltreating mothers. Development and Psychopathology, 32(2), 531-543. https://doi.org/10.1017/S0954579419000270

Patterson, G. R. (2002). The early development of coercive family process. In J. B. Reid, G. R. Patterson, \& J. Snyder (Eds.), Antisocial behavior in children and adolescents: A developmental analysis and model for intervention (pp. 25-44). American Psychological Association. https://doi.org/10.1037/10468-002

Peters, S., Calam, R., \& Harrington, R. (2005). Maternal attributions and expressed emotion as predictors of attendance at parent management training. Journal of Child Psychology and Psychiatry, 46(4), 436-448. https://doi.org/10.1111/j.1469-7610.2004.00365.x

Pollak, S. D., Cicchetti, D., Hornung, K., \& Reed, A. (2000). Recognizing emotion in faces: Developmental effects of child abuse and neglect. Developmental Psychology, 36(5), 679-688. https://doi.org/10.1037/0012-1649.36.5.679

Pollak, S. D., Klorman, R., Thatcher, J. E., \& Cicchetti, D. (2001). P3b reflects maltreated children's reactions to facial displays of emotion. Psychophysiology, 38(2), 267-274. https://doi.org/10.1111/1469-8986.3820267

Pollak, S. D., \& Sinha, P. (2002). Effects of early experience on children's recognition of facial displays of emotion. Developmental Psychology, 38(5), 784-791. https://doi.org/10.1037/0012-1649.38.5.784

Prinz, R. J., \& Miller, G. E. (1994). Family-based treatment for childhood antisocial behavior: Experimental influences on dropout and engagement. Journal of Consulting and Clinical Psychology, 62(3), 645-650. https://doi.org/10.1037/0022-006X.62.3.645 
Reyno, S. M., \& McGrath, P. J. (2006). Predictors of parent training efficacy for child externalizing behavior problems - a meta-analytic review. Journal of Child Psychology and Psychiatry, 47(1), 99-111. https://doi.org/10.1111/j.1469-7610.2005.01544.x

Riggins-Caspers, K. M., Cadoret, R. J., Knutson, J. F., \& Langbehn, D. (2003). Biologyenvironment interaction and evocative biology-environment correlation: Contributions of harsh discipline and parental psychopathology to problem adolescent behaviors. Behavior Genetics, 33(3), 205-220. https://doi.org/10.1023/A:1023434206261

Roth, R. M., Isquith, P. K., \& Gioia, G. A. (2005). BRIEF-A: Behavior Rating Inventory of Executive Function- Adult Version. Psychological Assessment Resources.

Schuhmann, E. M., Foote, R. C., Eyberg, S. M., Boggs, S. R., \& Algina, J. (1998). Efficacy of Parent-Child Interaction Therapy: Interim report of a randomized trial with short-term maintenance. Journal of Clinical Child Psychology, 27(1), 34-45. https://doi.org/10.1207/s15374424jccp2701_4

Schulz, K., Fan, J., Magidina, O., Marks, D., Hahn, B., \& Halperin, J. (2007). Does the emotional go/no-go task really measure behavioral inhibition? Convergence with measures on a non-emotional analog. Archives of Clinical Neuropsychology, 22(2), 151160. https://doi.org/10.1016/j.acn.2006.12.001

Schulz, K. P., Clerkin, S. M., Halperin, J. M., Newcorn, J. H., Tang, C. Y., \& Fan, J. (2009). Dissociable neural effects of stimulus valence and preceding context during the inhibition of responses to emotional faces. Human Brain Mapping, 30(9), 2821-2833. https://doi.org/10.1002/hbm.20706

Singh, N. N., Lancioni, G. E., Karazsia, B. T., Myers, R. E., Hwang, Y.-S., \& Anālayo, B. (2019). Effects of Mindfulness-Based Positive Behavior Support (MBPBS) training are 
equally beneficial for mothers and their children With Autism Spectrum Disorder or with intellectual disabilities. Frontiers in Psychology, 10, 385.

https://doi.org/10.3389/fpsyg.2019.00385

Singh, N. N., Singh, A. N., Lancioni, G. E., Singh, J., Winton, A. S. W., \& Adkins, A. D. (2010). Mindfulness training for parents and their children with ADHD increases the children's compliance. Journal of Child and Family Studies, 19(2), 157-166.

https://doi.org/10.1007/s10826-009-9272-z

Skowron, E. (2015). Understanding autonomic physiology and relationship processes in highrisk families. In The family emotional system: An integrative concept for theory, science, and practice (pp. 237-256). Rowman \& Littlefield.

Skowron, E. A., Cipriano-Essel, E., Benjamin, L. S., Pincus, A. L., \& Van Ryzin, M. J. (2013). Cardiac vagal tone and quality of parenting show concurrent and time-ordered associations that diverge in abusive, neglectful, and non-maltreating mothers. Couple and Family Psychology: Research and Practice, 2(2), 95-115. https://doi.org/10.1037/cfp0000005

Skowron, E. A., Loken, E., Gatzke-Kopp, L. M., Cipriano-Essel, E. A., Woehrle, P. L., Van Epps, J. J., Gowda, A., \& Ammerman, R. T. (2011). Mapping cardiac physiology and parenting processes in maltreating mother-child dyads. Journal of Family Psychology, 25(5), 663-674. https://doi.org/10.1037/a0024528

Skowron, E. A., \& Woehrle, P. (2012). Child maltreatment. In N. A. Fouad, J. A. Carter, \& L. M. Subich (Eds.), APA handbooks in psychology. APA handbook of counseling psychology, Vol. 2. Practice, interventions, and applications (p. 153-180). American Psychological Association. https://doi.org/10.1037/13755-007 
Smith, J. D., Woodhouse, S. S., Clark, C. A. C., \& Skowron, E. A. (2016). Attachment status and mother-preschooler parasympathetic response to the strange situation procedure. Biological Psychology, 114, 39-48. https://doi.org/10.1016/j.biopsycho.2015.12.008

Stith, S. M., Liu, T., Davies, L. C., Boykin, E. L., Alder, M. C., Harris, J. M., Som, A., McPherson, M., \& Dees, J. E. M. E. G. (2009). Risk factors in child maltreatment: A meta-analytic review of the literature. Aggression and Violent Behavior, 14(1), 13-29. https://doi.org/10.1016/j.avb.2006.03.006

Straus, M. A. (2001). Beating the devil out of them: Corporal punishment in American families and its effects on children. Transaction Publishers.

Sturge-Apple, M. L., Davies, P. T., Cicchetti, D., \& Fittoria, M. G. (2014). A typology of interpartner conflict and maternal parenting practices in high-risk families: Examining spillover and compensatory models and implications for child adjustment. Development and Psychopathology, 26(4pt1), 983-998. https://doi.org/10.1017/S0954579414000509

Task Force of the European Society of Cardiology. (1996). Heart rate variability: Standards of measurement, physiological interpretation, and clinical use. Circulation, 93(5), $1043-$ 1065. https://doi.org/10.1161/01.CIR.93.5.1043

Thomas, R., \& Zimmer-Gembeck, M. J. (2012). Parent-Child Interaction Therapy: An evidencebased treatment for child maltreatment. Child Maltreatment, 17(3), 253-266. https://doi.org/10.1177/1077559512459555

Toth, S. L., Gravener-Davis, J. A., Guild, D. J., \& Cicchetti, D. (2013). Relational interventions for child maltreatment: Past, present, and future perspectives. Development and Psychopathology, 25(4pt2), 1601-1617. https://doi.org/10.1017/S0954579413000795 
Valiente, C., Lemery-Chalfant, K., \& Reiser, M. (2007). Pathways to problem behaviors: Chaotic homes, parent and child effortful control, and parenting. Social Development, 16(2), 249-267. https://doi.org/10.1111/j.1467-9507.2007.00383.x

Webb, H. J., Thomas, R., McGregor, L., Avdagic, E., \& Zimmer-Gembeck, M. J. (2017). An evaluation of Parent-Child Interaction Therapy with and without motivational enhancement to reduce attrition. Journal of Clinical Child \& Adolescent Psychology, 46(4), 537-550. https://doi.org/10.1080/15374416.2016.1247357

Werba, B. E., Eyberg, S. M., Boggs, S. R., \& Algina, J. (2006). Predicting outcome in parentchild interaction therapy: Success and attrition. Behavior Modification, 30(5), 618-646. https://doi.org/10.1177/0145445504272977

Wierzbicki, M., \& Pekarik, G. (1993). A meta-analysis of psychotherapy dropout. Professional Psychology: Research and Practice, 24(2), 190-195. https://doi.org/10.1037/07357028.24.2.190

Youngstrom, E. A., \& De Los Reyes, A. (2015). Commentary: Moving toward cost-effectiveness in using psychophysiological measures in clinical assessment: validity, decision making, and adding value. Journal of Clinical Child and Adolescent Psychology, 44(2), 352-361. https://doi.org/10.1080/15374416.2014.913252 
Table 1. Means, ranges, and bivariate correlations among parent social cognitive and self-regulation predictors of PCIT attrition.

\begin{tabular}{|c|c|c|c|c|c|c|c|c|c|c|c|c|c|}
\hline Variable & $M$ & Min & Max & 1 & 2 & 3 & 4 & 5 & 6 & 7 & 8 & 9 & 10 \\
\hline 1. PAT Child Control Attribution & 3.45 & 2.00 & 4.50 & - & & & & & & & & & \\
\hline 2. PAT Parent Control Attribution & 4.34 & 2.67 & 6.38 & -0.06 & - & & & & & & & & \\
\hline 3. SASB Child Harsh Control & 69.66 & 0.00 & 200.00 & $0.19^{*}$ & 0.13 & - & & & & & & & \\
\hline 4. Emo \% False Alarms Anger & 0.07 & 0.00 & 0.48 & -0.04 & 0.14 & 0.13 & - & & & & & & \\
\hline 5. REDI Score & 3.78 & 2.91 & 4.91 & -0.14 & -0.17 & 0.08 & -0.10 & - & & & & & \\
\hline 6. BRIEF-A BRI Score & 54.72 & 38.00 & 84.00 & 0.06 & $-0.21^{*}$ & 0.14 & -0.01 & $0.36^{* *}$ & - & & & & \\
\hline 7. SSRT & 249.00 & 150.20 & 411.83 & -0.10 & -0.09 & 0.08 & -0.01 & 0.07 & 0.12 & - & & & \\
\hline 8. Baseline RSA & 5.98 & 2.77 & 9.85 & -0.12 & -0.11 & -0.14 & -0.03 & 0.05 & -0.06 & -0.11 & - & & \\
\hline 9. $\triangle \mathrm{RSA}$ Challenge (toy clean-up) & -0.16 & -3.05 & 2.70 & 0.13 & $0.18^{\wedge}$ & 0.02 & -0.11 & -0.01 & 0.05 & -0.03 & $-0.50^{* *}$ & - & \\
\hline 10. $\triangle$ RSA Social Engagement & 0.21 & -2.43 & 2.83 & 0.09 & 0.09 & -0.04 & -0.11 & -0.06 & -0.07 & -0.08 & $-0.37^{* *}$ & $0.68^{* *}$ & - \\
\hline 11. Proportion Negative Parenting & 0.07 & 0.00 & 0.19 & -0.02 & 0.06 & -0.04 & 0.08 & -0.01 & 0.07 & 0.10 & -0.10 & 0.10 & $0.18^{\wedge}$ \\
\hline
\end{tabular}

${ }^{\wedge} p<.1,{ }^{*} p<.05,{ }^{*} p<.01$. PAT = Parent Attribution Test, higher scores indicate greater perceived Child Control or Parent Control over parent-child interaction dynamics; SASB = Structural Analysis of Social Behavior, higher Child Harsh Control scores indicate greater perceived harsh and controlling behavior from child to parent; Emo \% False Alarms Anger = proportion of trials where neutral faces were misidentified as angry on the emotional go/no-go task, higher scores indicate greater threat sensitivity; REDI = Readiness for Parenting Change Inventory, higher scores indicate greater readiness to change; BRIEF-A = Behavioral Rating Inventory of Executive Functioning - Adult Version; BRI = Behavioral Regulation Index, higher scores indicate greater problems with behavioral regulation; SSRT = Stop Signal Reaction Time, higher scores indicate slower reaction time ; RSA $=$ Respiratory Sinus Arrhythmia; $\Delta$ RSA Challenge $=$ change in RSA from baseline to challenging cleanup task; $\Delta$ RSA Social Engagement $=$ change in RSA from baseline to social engagement task, higher scores indicate greater RSA increases (i.e., less RSA withdrawal); Proportion Negative Parenting $=$ higher scores indicate greater observed negative parenting. 
Table 2. Results of multinomial logistic regression parent self-regulation predicting PCIT engagement model.

\begin{tabular}{|c|c|c|c|c|c|c|c|c|c|}
\hline \multirow{3}{*}{$\begin{array}{l}\text { Predictor } \\
\text { BRIEF-A BRI Score }\end{array}$} & \multicolumn{3}{|c|}{ CDI Dropout } & \multicolumn{3}{|c|}{ PDI Dropout } & \multicolumn{3}{|c|}{ Completed Treatment } \\
\hline & \multirow{2}{*}{$\begin{array}{c}\text { Odds Ratio } \\
0.90\end{array}$} & \multicolumn{2}{|c|}{ Estimate (SE) } & \multirow{2}{*}{$\begin{array}{c}\text { Odds Ratio } \\
1.12\end{array}$} & \multicolumn{2}{|c|}{ Estimate (SE) } & \multirow{2}{*}{$\begin{array}{c}\text { Odds Ratio } \\
0.88\end{array}$} & \multicolumn{2}{|c|}{ Estimate (SE) } \\
\hline & & -0.08 & $(0.25)$ & & 0.10 & $(0.26)$ & & -0.15 & $(0.34)$ \\
\hline SSRT & 1.29 & 0.20 & $(0.29)$ & 1.01 & 0.01 & $(0.23)$ & 0.81 & -0.26 & $(0.31)$ \\
\hline Baseline RSA & 1.68 & 0.41 & $(0.29)$ & 1.22 & 0.17 & $(0.36)$ & 1.08 & 0.09 & $(0.33)$ \\
\hline$\triangle$ RSA Challenge & $0.38^{* *}$ & -0.77 & (0.29) & $0.41^{\wedge}$ & -0.77 & $(0.42)$ & $0.50^{*}$ & -0.85 & $(0.36)$ \\
\hline$\triangle$ RSA Soc Engagement & $2.32^{*}$ & 0.67 & $(0.31)$ & $3.10^{* * *}$ & 0.99 & $(0.27)$ & $1.83^{\wedge}$ & 0.74 & $(0.40)$ \\
\hline Negative Parenting & $1.96^{*}$ & 0.53 & $(0.24)$ & $1.78^{\wedge}$ & 0.51 & $(0.29)$ & $1.57^{\wedge}$ & 0.55 & $(0.30)$ \\
\hline \multicolumn{10}{|c|}{ Odds of CDI Dropout vs. } \\
\hline \multirow[t]{2}{*}{ Predictor } & \multicolumn{3}{|c|}{ Pre-Treatment Dropout } & \multicolumn{3}{|c|}{ PDI Dropout } & \multicolumn{3}{|c|}{ Completed Treatment } \\
\hline & Odds Ratio & \multicolumn{2}{|c|}{ Estimate (SE) } & Odds Ratio & \multicolumn{2}{|c|}{ Estimate (SE) } & Odds Ratio & \multicolumn{2}{|c|}{ Estimate (SE) } \\
\hline BRIEF-A BRI Score & 1.11 & 0.08 & $(0.25)$ & 1.25 & 0.35 & $(0.53)$ & 0.98 & -0.03 & $(0.43)$ \\
\hline SSRT & 0.78 & -0.20 & $(0.29)$ & 0.78 & -0.38 & $(0.49)$ & $0.63^{\wedge}$ & -0.67 & (0.36) \\
\hline Baseline RSA & 0.60 & -0.41 & $(0.29)$ & 0.73 & -0.51 & $(0.70)$ & 0.64 & -0.63 & (0.44) \\
\hline$\triangle$ RSA Challenge & $2.63^{* *}$ & 0.77 & (0.29) & 1.09 & 0.14 & $(0.75)$ & 1.32 & 0.39 & (0.48) \\
\hline$\triangle \mathrm{RSA}$ Soc Engagement & $0.43^{*}$ & -0.67 & $(0.31)$ & 1.34 & 0.46 & $(0.80)$ & 0.79 & -0.33 & $(0.45)$ \\
\hline Negative Parenting & $0.51^{*}$ & -0.53 & $(0.24)$ & 0.91 & -0.15 & $(0.59)$ & 0.80 & -0.32 & (0.45) \\
\hline
\end{tabular}

Odds of PDI Dropout vs.

Predictor

BRIEF-A BRI Score

SSRT

Baseline RSA

$\triangle \mathrm{RSA}$ Challenge

$\triangle$ RSA Soc Engagement

Negative Parenting
Pre-Treatment Dropout

CDI Dropout

Completed Treatment

\begin{tabular}{|c|c|c|c|c|c|c|c|c|}
\hline Odds Ratio & \multicolumn{2}{|c|}{ Estimate (SE) } & \multirow{2}{*}{$\frac{\text { Odds Ratio }}{0.80}$} & \multicolumn{2}{|c|}{ Estimate (SE) } & \multirow{2}{*}{$\frac{\text { Odds Ratio }}{0.79}$} & \multicolumn{2}{|c|}{ Estimate (SE) } \\
\hline 0.89 & -0.10 & $(0.26)$ & & -0.35 & $(0.53)$ & & -0.45 & $(0.56)$ \\
\hline 0.99 & -0.01 & $(0.23)$ & 1.28 & 0.38 & $(0.49)$ & 0.80 & -0.42 & $(0.53)$ \\
\hline 0.82 & -0.17 & $(0.36)$ & 1.38 & 0.51 & $(0.70)$ & 0.89 & -0.23 & $(0.74)$ \\
\hline $2.42^{\wedge}$ & 0.77 & $(0.42)$ & 0.92 & -0.14 & $(0.75)$ & 1.21 & 0.35 & $(0.84)$ \\
\hline $0.32^{* * *}$ & -0.99 & (0.27) & 0.75 & -0.46 & $(0.80)$ & 0.59 & -0.99 & (0.61) \\
\hline $0.56^{\wedge}$ & -0.51 & $(0.29)$ & 1.10 & 0.15 & (0.59) & 0.88 & -0.24 & $(0.58)$ \\
\hline
\end{tabular}

Odds of Completing Treatment vs.

Predictor

Pre-treatment Dropout

CDI Dropout

PDI Dropout

\begin{tabular}{|c|c|c|c|c|c|c|c|c|}
\hline Odds Ratio & \multicolumn{2}{|c|}{ Estimate (SE) } & Odds Ratio & \multicolumn{2}{|c|}{ Estimate (SE) } & \multirow{2}{*}{$\frac{\text { Odds Ratio }}{1.27}$} & \multicolumn{2}{|c|}{ Estimate (SE) } \\
\hline 1.13 & 0.15 & $(0.34)$ & 1.02 & 0.03 & $(0.43)$ & & 0.45 & $(0.56)$ \\
\hline 1.24 & 0.26 & $(0.31)$ & $1.60^{\wedge}$ & 0.67 & $(0.36)$ & 1.25 & 0.42 & $(0.53)$ \\
\hline 0.93 & -0.09 & $(0.33)$ & 1.56 & 0.63 & $(0.44)$ & 1.13 & 0.23 & $(0.74)$ \\
\hline $2.00^{*}$ & 0.85 & $(0.36)$ & 0.76 & -0.39 & $(0.48)$ & 0.83 & -0.35 & $(0.84)$ \\
\hline $0.55^{\wedge}$ & -0.74 & $(0.40)$ & 1.27 & 0.33 & $(0.45)$ & 1.69 & 0.99 & $(0.61)$ \\
\hline $0.64^{\wedge}$ & -0.55 & $(0.30)$ & 1.25 & 0.32 & $(0.45)$ & 1.14 & 0.24 & (0.58) \\
\hline
\end{tabular}

$\hat{p}<.10,{ }^{*} p<.05,{ }^{* *} p<.01,{ }^{* * *} p<.001$. Double lines divide treatment phases that occur before the target category versus after. 
Table 3. Results of multinomial logistic regression parent social cognitive processes predicting PCIT engagement model.

Odds of Non-Engagement (Pre-Treatment Dropout) vs.

Predictor

CDI Dropout

PDI Dropout

Completed Treatment

\begin{tabular}{|c|c|c|c|c|c|c|c|c|c|}
\hline \multirow[b]{2}{*}{ PAT Child Control Attribution } & \multirow{2}{*}{$\begin{array}{c}\text { Odds Ratio } \\
1.22\end{array}$} & \multicolumn{2}{|c|}{ Estimate (SE) } & \multirow{2}{*}{$\begin{array}{c}\text { Odds Ratio } \\
1.91^{*}\end{array}$} & \multicolumn{2}{|c|}{ Estimate (SE) } & \multirow{2}{*}{$\begin{array}{c}\text { Odds Ratio } \\
1.61^{*}\end{array}$} & \multicolumn{2}{|c|}{ Estimate (SE) } \\
\hline & & 0.21 & $(0.33)$ & & 0.49 & $(0.21)$ & & 0.49 & $(0.22)$ \\
\hline PAT Parent Control Attribution & $1.63^{\wedge}$ & 0.51 & $(0.29)$ & 1.37 & 0.24 & $(0.27)$ & 1.29 & 0.27 & $(0.28)$ \\
\hline SASB Child Harsh Control & 0.91 & -0.09 & $(0.27)$ & $0.42^{* *}$ & -0.65 & $(0.23)$ & 0.75 & -0.31 & $(0.28)$ \\
\hline Emo \% False Alarms Anger & $0.50^{* * *}$ & -0.72 & $(0.18)$ & 0.93 & -0.05 & $(0.24)$ & 1.28 & 0.25 & $(0.32)$ \\
\hline REDI Score & 0.94 & -0.07 & $(0.31)$ & 0.62 & -0.37 & $(0.26)$ & $0.58^{*}$ & -0.57 & $(0.23)$ \\
\hline Negative Parenting & $1.71^{* *}$ & 0.56 & $(0.21)$ & $1.94^{*}$ & 0.50 & $(0.22)$ & 1.40 & 0.35 & $(0.26)$ \\
\hline \multicolumn{10}{|l|}{ Odds of CDI Dropout vs. } \\
\hline \multirow[t]{2}{*}{ Predictor } & \multicolumn{3}{|c|}{ Pre-Treatment Dropout } & \multicolumn{3}{|c|}{ PDI Dropout } & \multicolumn{3}{|c|}{ Completed Treatment } \\
\hline & Odds Ratio & Estimat & e (SE) & Odds Ratio & Estima & te (SE) & Odds Ratio & Estim & te (SE) \\
\hline PAT Child Control Attribution & 0.83 & -0.21 & $(0.33)$ & 1.57 & 0.38 & $(0.29)$ & 1.32 & 0.24 & $(0.25)$ \\
\hline PAT Parent Control Attribution & $0.61^{\wedge}$ & -0.51 & $(0.29)$ & 0.84 & -0.15 & $(0.33)$ & 0.79 & -0.20 & $(0.27)$ \\
\hline SASB Child Harsh Control & 1.09 & 0.09 & $(0.27)$ & $0.46^{* *}$ & -0.65 & $(0.22)$ & 0.82 & -0.18 & $(0.22)$ \\
\hline Emo \% False Alarms Anger & $2.00^{* * *}$ & 0.72 & $(0.18)$ & $1.87^{* *}$ & 0.53 & $(0.20)$ & $2.56^{* * *}$ & 0.81 & (0.17) \\
\hline REDI Score & 1.07 & 0.07 & $(0.31)$ & 0.66 & -0.35 & $(0.29)$ & $0.62^{\wedge}$ & -0.41 & $(0.24)$ \\
\hline Negative Parenting & $0.59^{* *}$ & -0.56 & $(0.21)$ & 1.14 & 0.11 & $(0.31)$ & 0.82 & -0.17 & $(0.22)$ \\
\hline
\end{tabular}

Odds of PDI Dropout vs.

Predictor

Pre-Treatment Dropout

CDI Dropout

Completed Treatment

PAT Child Control Attribution

Odds Ratio Estimate (SE)

$\begin{array}{lll}\mathbf{0 . 5 2}^{*} & -0.49 & (0.21)\end{array}$

\begin{tabular}{ccc} 
Odds Ratio & \multicolumn{2}{l}{ Estimate (SE) } \\
\hline 0.64 & -0.38 & $(0.29)$
\end{tabular}

Odds Ratio Estimate (SE)

PAT Parent Control Attribution

0.73

$\begin{array}{ll}-0.24 & (0.27)\end{array}$

$2.36^{* *}$

$0.65 \quad(0.23)$

1.19

$0.15 \quad(0.33)$

SASB Child Harsh Control

1.07

$0.05 \quad(0.24)$

$2.16^{* *}$

$0.65 \quad(0.22)$
0.53

$0.54^{* *}$

$-0.53 \quad(0.20)$
0.35

1.52

$0.35 \quad(0.29)$
0.11

1.63

$\begin{array}{ll}0.37 & (0.26)\end{array}$

0.88

$\begin{array}{ll}-0.11 & (0.31)\end{array}$

\begin{tabular}{||lll}
\hline 0.84 & -0.24 & $(0.41)$ \\
0.94 & -0.08 & $(0.47)$ \\
$1.76^{*}$ & 0.79 & $(0.33)$ \\
1.37 & 0.44 & $(0.46)$ \\
0.94 & -0.09 & $(0.44)$ \\
0.72 & -0.46 & $(0.45)$ \\
\hline
\end{tabular}

Odds of Completing Treatment vs.

Predictor

\section{PAT Child Control Attribution}

PAT Parent Control Attribution

SASB Child Harsh Control

Emo \% False Alarms Anger

REDI Score

Negative Parenting
Pre-treatment Dropout

CDI Dropout

\begin{tabular}{|c|c|c|c|c|c|}
\hline Odds Ratio & \multicolumn{2}{|c|}{ Estimate (SE) } & \multirow{2}{*}{$\begin{array}{c}\text { Odds Ratio } \\
0.76\end{array}$} & \multicolumn{2}{|c|}{ Estimate (SE) } \\
\hline $0.62^{*}$ & -0.49 & $(0.28)$ & & -0.24 & $(0.25)$ \\
\hline 0.78 & -0.27 & $(0.22)$ & 1.26 & 0.20 & (0.27) \\
\hline 1.34 & 0.31 & $(0.28)$ & 1.23 & 0.18 & $(0.22)$ \\
\hline 0.78 & -0.25 & (0.32) & $0.39^{* * *}$ & -0.81 & (0.17) \\
\hline $1.73^{*}$ & 0.57 & $(0.23)$ & $1.62^{\wedge}$ & 0.41 & (0.24) \\
\hline 0.71 & -0.35 & $(0.26)$ & 1.22 & 0.17 & $(0.22)$ \\
\hline
\end{tabular}

${ }^{p} p<.10,{ }^{*} p<.05,{ }^{* *} p<.01,{ }^{* * *} p<.001$. Double lines divide treatment phases that occur before the target category versus after.

PDI Dropout

\begin{tabular}{ccc||}
\hline Odds Ratio & \multicolumn{2}{c|}{ Estimate (SE) } \\
\hline 1.19 & 0.24 & $(0.41)$ \\
1.06 & 0.08 & $(0.48)$ \\
$\mathbf{0 . 5 7}^{*}$ & -0.79 & $(0.33)$ \\
0.73 & -0.44 & $(0.46)$ \\
1.06 & -0.09 & $(0.44)$ \\
1.39 & 0.46 & $(0.45)$ \\
\hline
\end{tabular}

